\title{
Structural Basis for CAL1-Mediated Centromere Maintenance
}

Bethan Medina-Pritchard1', Vasiliki Lazou¹, Juan Zou1, Olwyn Byron², Juri Rappsilber ${ }^{1,3}$, Patrick Heun ${ }^{1}$ and A. Arockia Jeyaprakash ${ }^{1^{*}}$

${ }^{1}$ Wellcome Centre for Cell Biology, University of Edinburgh, Edinburgh, EH9 3BF, UK

${ }^{2}$ School of Life Sciences, University of Glasgow, Glasgow, G12 8TA, UK

${ }^{3}$ Institute of Biotechnology, Technische Universität Berlin, 13355 Berlin, Germany

*email: jeyaprakash.arulanandam@ed.ac.uk 


\section{Summary}

Centromeres are microtubule attachment sites on chromosomes defined by the enrichment of CENP-A-containing nucleosomes. To preserve centromere identity, CENP-A must be escorted to centromeres by a CENP-A-specific chaperone for deposition. Despite this essential requirement, many eukaryotes differ in the composition of players involved in centromere maintenance highlighting the plasticity of this process. In humans, CENP-A recognition and centromere targeting is achieved by HJURP and the Mis18 complex, respectively. Here, using crystal structures, we show how Drosophila CAL1, an evolutionarily distinct CENP-A chaperone, targets CENP-A to the centromere receptor CENP-C without the requirement of the Mis18 complex: while the $\mathrm{N}$-terminal CAL1 fragment (CAL11-160) wraps around CENP-A/H4 through multiple physical contacts, the C-terminal CAL1 fragment (CAL $1_{\text {893-914) }}$ directly binds CENP-C cupin dimer. Our work shows CAL1, though divergent at the primary structure, employs evolutionarily conserved and adaptive structural principles to recognise $\mathrm{CENP}-\mathrm{A} / \mathrm{H} 4$ and $\mathrm{CENP}-\mathrm{C}$ providing insights into the minimalistic principles underlying centromere maintenance.

\section{Key Words}

CAL1, CENP-A, CENP-C, centromeres, HJURP, Scm3, Mis18 complex, kinetochore, chromosome segregation 


\section{Introduction}

Centromeres are specialised chromosomal regions that act as a platform for the assembly of kinetochores, the microtubule anchoring sites essential for chromosome segregation during mitosis and meiosis (Musacchio and Desai, 2017). Unlike budding yeast where DNA sequence is sufficient to define centromere identity, in most eukaryotes centromeres are defined by the enrichment of unique nucleosomes containing the histone $\mathrm{H} 3$ variant CENP-A (Sekulic and Black, 2012, Zasadzinska and Foltz, 2017). As a consequence, maintenance of CENP-A containing nucleosomes is essential for preserving centromere identity through generations of cell cycles. This is achieved through an epigenetic mechanism that relies on CENP-A as an epigenetic mark (Zasadzinska and Foltz, 2017, Westhorpe and Straight, 2014, McKinley and Cheeseman, 2016, Musacchio and Desai, 2017).

Unlike canonical chromatin maintenance where histone $\mathrm{H} 3$ is deposited concomitantly with DNA replication, the centromeric chromatin maintenance is decoupled from DNA replication. As a result, CENP-A levels in the sister chromatids are reduced by half during replication (Hemmerich et al., 2008, Jansen et al., 2007, Mellone et al., 2011, Dunleavy et al., 2009, Lidsky et al., 2013). To ensure stable centromere maintenance, CENP-A nucleosome must be brought back to their original levels through active CENP-A deposition. The timing of CENP-A deposition varies among species, however, the underlying mechanisms appear to share significant similarity (Zasadzinska and Foltz, 2017). A central player in this process is the CENP-A-specific chaperone HJURP in human and its homologue Scm3 in fungi (Kato et al., 2007, Foltz et al., 2009, Dunleavy et al., 2011, Pidoux et al., 2009, Sanchez-Pulido et al., 2009). Both HJURP and Scm3 can bind the CENP-A-Histone H4 (CENP-A/H4) heterodimer in its pre-nucleosomal form and these complexes are then targeted to centromeres by the Mis18 complex (Hayashi et al., 2014, Fujita et al., 2007, Nardi et al., 2016, Stellfox et al., 2016, McKinley and Cheeseman, 2014, Moree et al., 2011, Dambacher et al., 2012, French et al., 2017, Hori et al., 2017). While the human Mis18 complex is composed of Mis18 $\alpha$, Mis $18 \beta$ and Mis18BP1, the fission yeast Mis18 complex consists of Mis18, Mis16, Eic1 and Eic2, where 
Eic1 and Eic2 are proposed to be a functional equivalents of human Mis18BP1 (Subramanian et al., 2014, Hayashi et al., 2014, Fujita et al., 2007). The timing of Mis18 complex assembly, its centromere targeting and subsequent CENP-A deposition is suggested to be tightly controlled by the kinase activities of CDK and PIk1 (McKinley and Cheeseman, 2014, Silva et al., 2012, French and Straight, 2019, Stankovic et al., 2017). While we know the identity of key players involved in centromere maintenance, molecular and mechanistic understanding of their intermolecular cooperation are just emerging (Spiller et al., 2017, Pan et al., 2017, Nardi et al., 2016, Stellfox et al., 2016).

Strikingly, Drosophila species have regional centromeres defined by the presence of CENPA (also called CID) but lack clear homologues of HJURP and the subunits of the Mis18 complex. Instead, fly-specific CAL1 appears to combine both the roles of HJURP and the Mis18 complex: pre-nucleosomal CENP-A recognition and its targeting to the centromere for deposition, respectively (Phansalkar et al., 2012). Targeting CAL1 to non-centromeric DNA in Drosophila cells recruited CENP-A and established centromeres capable of assembling kinetochore proteins and microtubule attachments (Chen et al., 2014). These observations and the ability of CAL1 to bind CENP-A/H4 and CENP-C with its $\mathrm{N}$ - and C-terminal regions, respectively, collectively established CAL1 as a 'self-sufficient' CENP-A-specific assembly factor in Drosophila (Chen et al., 2014, Schittenhelm et al., 2010). However, structural level mechanistic understanding of how CAL1 binds CENP-A/H4 and CENP-C to facilitate the establishment and maintenance of centromeres is yet to be determined. The simplistic nature of the centromere maintenance pathway in Drosophila makes it a unique model system to understand the fundamentally conserved structural principles underlying centromere maintenance.

In this study, we present the structural basis for the recognition of CENP-A/H4 and CENP-C by CAL 1 . Our analysis reveals that although CAL1 does not share noticeable sequence similarity with its human or fission yeast counterpart, it recognises CENP-A/H4 using 
conserved structural principles. We also provide the structural framework of interactions responsible for CENP-C recognition by CAL1. The structural analysis, together with validation of structure-guided mutants in vitro and in cells, provides the structural basis for the mechanism by which CAL1 solely recognises and targets CENP-A to centromeres to maintain centromere identity in flies.

\section{Results}

The N-terminus of CAL1 forms a heterotrimer with the histone fold domain of CENP-A and $\mathrm{H} 4$

Secondary structure prediction analysis indicated that CAL1 is likely to be a predominantly unstructured protein, although it includes an N-terminal domain spanning amino acid (aa) residues 1-200 predicted to fold into $\alpha$ helices (Figure S1A and B). With the aim of structurally characterising the intermolecular interactions responsible for CAL1 binding to CENP-A/H4, we reconstituted a protein complex containing the $\mathrm{N}$-terminal 160 aa residues of CAL1 (CAL1 1 160), a putative histone fold domain of CENP-A (CENP-A 101-225 $)$ and H4 (His-CAL1 $1_{1-160}-$ CENP$\left.\mathrm{A}_{101-225}-\mathrm{H} 4\right)$ (Figure 1A) using recombinant proteins as previously reported (Chen et al., 2014). Limited proteolysis experiments performed on CAL1 ${ }_{1-160}-C_{E N P}-A_{101-225}-H 4$ complex using different proteases suggested that a CENP-A fragment containing aa residues 144-255 (CENP-A ${ }_{144-255}$ ) is sufficient to interact with CAL1 and H4 (results not shown). Subsequently, using CAL1 1-160, CENP-A 144-255 $_{1}$ and $\mathrm{H} 4$ we reconstituted a truncated protein complex (HisCAL11-160-CENP-A $\left.{ }_{144-225}-\mathrm{H} 4\right)$. The molecular weights measured for His-CAL11-160-CENP$\mathrm{A}_{101-225}-\mathrm{H} 4$ and His-CAL1 ${ }_{1-160}-\mathrm{CENP}-\mathrm{A}_{144-225}-\mathrm{H} 4$ using $\underline{\text { Size }}$ Exxclusion $\underline{\text { Chromatography }}$

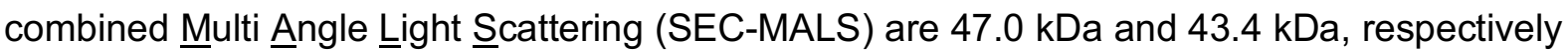
(Figure S1C). These values match with calculated molecular weights for a 1:1:1 hetero trimeric assembly for both complexes (46.7 kDa and $41.7 \mathrm{kDa}$ for His-CAL11-160-CENP-A ${ }_{101-225}-\mathrm{H} 4$ and His-CAL1 1-160-CENP-A ${ }_{144-225}-\mathrm{H} 4$, respectively) and in agreement with our previous report (Roure et al., 2019). This observation is in striking agreement with the subunit stoichiometry of the human pre-nucleosomal CENP-A/H4 in complex with HJURP (Hu et al., 2011). 


\section{Structure determination of CAL1 1-160-CENP-A/H4 complex}

Extensive crystallisation trials with CAL1 ${ }_{1-160}-\mathrm{CENP}-\mathrm{A}_{101-225}-\mathrm{H} 4$ and $\mathrm{CAL} 1_{1-160}-\mathrm{CENP}-\mathrm{A}_{144-}$ ${ }_{225}-\mathrm{H} 4$ yielded two different crystal forms, form I and form II, that diffracted X-rays to about 3.5 $\AA$ (form I) and $4.5 \AA$ (form II) (Table S1). Molecular replacement was performed for the dataset collected from form I using the coordinates of Drosophila melanogaster $(d m)$ H3/H4 heterodimer (deduced from the structure of $d m$ nucleosome core particle, pdb 2PYO) (Clapier et al., 2008). Molecular replacement solution yielded initial phases sufficient for subsequent rounds of model building and refinement (Figure S2A). The final model included residues 18 to 46 of CAL1, 147 to 220 of CENP-A and 28 to 98 of $\mathrm{H} 4$ and was refined to an $\mathrm{R}$ factor $25.5 \%$ and $\mathrm{R}_{\text {free }}$ factor $28.4 \%$ (Figure $1 \mathrm{~B}$, Table S1). Although we used a CAL1 fragment spanning residues 1-160 in the crystallisation experiment, the calculated electron density map accounted only for CAL1 residues 14-48. Considering these crystals took more than a year to form, we concluded that CAL1 was proteolytically cleaved, which may have facilitated the crystallisation of a truncated complex.

The refined model obtained using crystal form I was used as a template in molecular replacement to determine the structure of crystal form II (Figure 1C and S2B). The difference electron density map calculated using the molecular replacement solution revealed unambiguous density for most main chain atoms of CAL11-160. While side chain electron densities are well defined for CAL1 residues 7 to 47 , only the main chain could be modelled for rest of the CAL1. Considering the modest resolution of the structure, intermolecular interactions stabilising the CAL1-CENP-A/H4 complex were further analysed using chemical

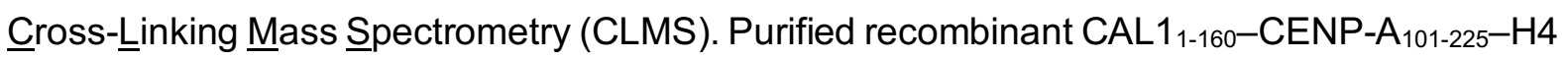
complex was crosslinked using EDC, a zero-length crosslinker that covalently links carboxylate groups of Asp or Glu residues with primary amines of Lys and N-terminus, or hydroxyl group of Ser, Thr and Tyr. The crosslinked peptides obtained from the trypsin digestion of the crosslinked sample were analysed by mass spectrometry to identify intra- and 
intermolecular contacts (Figure S3). Notably, the data revealed several intramolecular crosslinks between the $\mathrm{N}$ - and $\mathrm{C}$-terminal regions of CAL $1_{1-160,}$ suggesting a direct interaction between these regions (Figure S3). This information was particularly helpful in tracing the backbone atoms of residues beyond CAL1 residue 47 within the electron density map.

\section{Overall structure of CENP-A/H4 assembly}

The structures obtained from two different crystal forms together provide key insights into the overall architecture of the assembly (Figure 1B and C). CENP-A residues 147 to 220 form the histone fold domain with characteristic $\alpha 1, \alpha 2$ and $\alpha 3$ helices formed by residues $150-164$, 174-201 and 207-220, respectively. The corresponding $\alpha 1, \alpha 2$ and $\alpha 3$ residues of histone $\mathrm{H} 4$ are $30-44,51-78$ and $82-94$, respectively. Structural superposition analysis showed that CENP-A/H4 heterodimer aligns well with $\mathrm{H} 3 / \mathrm{H} 4$ heterodimer with a root mean square deviation (rmsd) of $1.2 \AA$ (Figure S4A). This suggests that both $\mathrm{H} 3$ and CENP-A use an identical mode of $\mathrm{H} 4$ binding. However, CENP-A $\alpha 1, \mathrm{H} 4 \alpha 3$ and C-terminal tail show conformational variations in the CAL1-bound CENP-A/H4 complex, likely due to CAL1 binding (Figure S4B). Particularly, in the $\mathrm{H} 3 / \mathrm{H} 4$ structure, the C-terminal tail of $\mathrm{H} 4$ folds back and makes contacts with the $\mathrm{H} 3 \alpha 3$ residues close to $\mathrm{H} 3$ loop $\mathrm{L} 1$, resembling CAL1 interaction at the equivalent region of CENP-A in the CAL1-bound CENP-A/H4 structure. The H4 C-terminal tail possibly swings away from this site upon CAL1 binding. Overall structure of $d m$ CENP$\mathrm{A} / \mathrm{H} 4$ is very similar to human CENP-A/H4 as these structures superpose well with a rmsd of $1.1 \AA$ (Figure S4C). However, noticeable conformational variation is seen in loop L1, possibly to accommodate the amino acid variations between HJURP and CAL1 (Figure S4B and S4C).

\section{CAL1 binds CENP-A/H4 heterodimer through multiple physical contacts}

CAL $1_{1-160}$ is almost entirely made of $\alpha$ helices that make multiple contacts with CENP-A/H4 heterodimer by wrapping around it (Figure 1C and 2A). Most CENP-A contacts are made by CAL1 helices $\alpha 1$ and $\alpha 2$ and loop L1, which interact with the CENP-A helices $\alpha 2, \alpha 1$ and loop 
L1 respectively involving a total interface area of about $940 \AA^{2}$. Particularly, while the Nterminal half of CAL1 $\alpha 1$ packs against CENP-A $\alpha 2$ involving electrostatic (CAL1 R18 with CENP-A Q90) and hydrophobic (involving CAL1 L11 and M14) interactions, the C-terminal half, mainly aa residues W22 and F29 are sandwiched between CENP-A $\alpha 2$ and H4 $\alpha 3$ (Figure 2A). CAL1 L1 crosses over CENP-A L1 to facilitate CAL1 $\alpha 2$ interaction with CENP-A $\alpha 3$. In addition, CAL1 $\alpha 4$ contacts both CENP-A $\alpha 2$ and $\alpha 3$ involving an interface area of about $80 \AA^{2}$. These CAL1-CENP-A interactions appear to be further stabilised by CAL1 $\alpha 5$ and $\alpha 6$ which together with CAL1 $\alpha 1$ make an intramolecular helical bundle resembling a latch that restrains the position of $\alpha 1$ helix (Figure $1 \mathrm{C}$ ).

\section{Hydrophobic interactions involving CAL1 W22 and F29 are critical for CENP-A/H4}

\section{binding}

Considering the extent of contacts made by the $\mathrm{N}$-terminal 50 aa residues of CAL 1 , we checked whether CAL1 $1_{1-50}$ is sufficient to interact with CENP-A/H4. Using bacterially

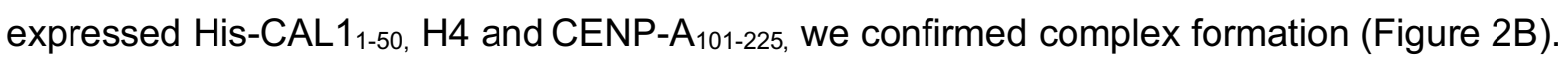
Further characterisation using SEC-MALS showed that CAL1 ${ }_{1-50}-\mathrm{CENP}-\mathrm{A}_{101-225}-\mathrm{H} 4$ is a $1: 1: 1$ complex with a measured molecular weight of $39.6 \mathrm{kDa}$ (calculated molecular weight 34.1 kDa) (Figure 2B).

Within CAL1 the conserved residues in $\alpha 1$ : W22 and F29, and in $\alpha 2$ : F43 are completely buried in the complex, so we hypothesised that these interactions are crucial for CENP-A/H4 binding (Figure 2A). To test this, we produced recombinant His-CAL11-160 carrying either F43R, W22A/F29A or W22R/F29R mutations and tested their ability to interact with CENP-A/H4 complex in a nickel-NTA pull down assay. His-CAL1 $1_{1-160}$ was mixed with molar excess of CENP-A/H4 complex, then incubated with nickel-NTA, to capture the His-CAL1 $1_{1-160}$ and any proteins bound to it. Beads were then washed to remove any unbound proteins. Analysis by SDS-PAGE revealed that while the F43R mutation had no effect on CAL1 $1_{1-160}$ binding, the 
W22 and F29 mutations reduced the ability of CAL $1_{1-160}$ to capture CENP-A/H4 compared with the WT protein (Figure 2C).

To validate the requirement of these interactions in vivo, we expressed CENP-A-GFP-Lacl in U2OS cells containing a synthetic array with a LacO sequence integrated in a chromosome arm (Janicki et al., 2004), and analysed its ability to recruit CAL1-V5 (Roure et al., 2019). When CENP-A-GFP-Lacl was tethered to the LacO site, CAL1wt was able to recruit CENP-A to the LacO site (Figure 2D). CAL $1_{\mathrm{F} 43 \mathrm{R}}$ caused a 3 -fold reduction in the levels co-localising with CENP-A. However, when CAL1w22/F29 mutants were used for in vivo tethering, they showed very little (Ala mutant) or no localisation (Arg mutant) to the LacO with CENP-A-GFPLacl, suggesting that these residues are crucial for CENP-A deposition in the cell.

\section{CAL1 uses conserved and adaptive interactions to recognise Drosophila CENP-A/H4}

Structural superposition of CAL1-CENP-A/H4 onto its respective human and Kluyveromyces lactis structures, HJURP-CENP-A/H4 (PDB: 3R45) (Hu et al., 2011) and Scm3-CENP-A/H4 (PDB: 2YFV) (Cho and Harrison, 2011) showed that CAL1 employs a broadly similar mode of CENP-A recognition with a few striking differences (Figure $3 A$ ). All CENP-A chaperones compared here use their $\alpha 1$ helix to interact with $\alpha 2$ of CENP-A in an anti-parallel fashion, occluding the tetramerisation of CENP-A/H4 heterodimers. However, in CAL1 the upstream segment of $\alpha 1$ swings away from CENP-A as compared with its counterpart in HJURP and Scm3. Structural superposition-based sequence alignments showed a key amino acid variation in $d m$ CENP-A at position 86 as compared with human and yeast CENP-A: Ala is replaced with Met, an amino acid with a long side chain, which appears to push CAL1 $\alpha 1$ away from it. This apparent weakening of CAL1 $\alpha 1-$ CENP-A $\alpha 2$ interaction is likely to be compensated by CAL $1 \alpha 5$ and $\alpha 6$ which together restrains the position of $\alpha 1$ helix by forming a helical bundle. Notably, loop L1 of both CAL1 and HJURP interacts with CENP-A L1 through main chain hydrogen bonding interactions. However, the secondary structural element 
downstream of L1 that interacts with the hydrophobic groove formed by CENP-A $\alpha 1$ and $\alpha 2$ is a three stranded $\beta$ sheet in HJURP whilst it is an $\alpha$ helix in CAL1. Strikingly, unlike other histone chaperones, CAL1 shields CENP-A $\alpha 3$ through downstream $\alpha$ helical elements (Figure 1 and 3). This intermolecular interaction appears to be critical for CENP-A recognition as a CENP-A chimera where CENP-A $\alpha 3$ was replaced with histone $\mathrm{H} 3 \alpha 3$ failed to associate with centromeres (Roure et al., 2019).

\section{CAL1 recognises amino acid variations unique to CENP-A}

The histone fold domain of CENP-A and histone $\mathrm{H} 3$ share $31 \%$ sequence identity. To understand how CAL1 differentiates CENP-A from histone H3 we looked for conserved CENPA-specific amino acid variations in several Drosophila species and compared these variations against $d m$ histone $\mathrm{H} 3$ (Figure $3 \mathrm{~B}$ ). This analysis together with the structural superposition of CENP-A onto histone $\mathrm{H} 3$ revealed several residues unique to CENP-A within the CAL1 binding region potentially responsible for CENP-A specificity: Ser154, Met186 and Gln190. The equivalent residues in histone $\mathrm{H} 3$ are Gln, Ala and Gly, respectively. To evaluate if any of these specific amino acid variations is responsible for providing CENP-A specificity, we made several recombinant CENP-A mutants where Ser154, Met186 and Gln190 are mutated

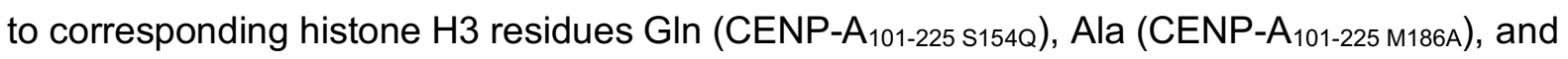

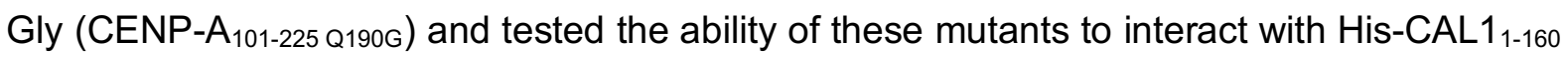
in a nickel-NTA pull down assay (Figure 3C). While His-CAL11-160 interacted with CENP-A mutants harbouring single 'histone H3-like' mutations as efficiently as it does the WT CENPA, combining three 'histone $\mathrm{H} 3$-like' mutations resulted in a noticeable reduction in CAL1 binding (Figure $3 C$ ). This suggests that CAL1 achieves CENP-A specificity by recognising multiple CENP-A-specific amino acid variations.

CAL1 chaperones CENP-A/H4 by shielding protein/DNA interaction surfaces crucial for nucleosome assembly 
Histone chaperones are key regulators of nucleosome assembly. This function is achieved by ensuring the correct histone incorporation in a spatio-temporally controlled manner. To understand how CAL1 exerts its CENP-A chaperone function, we performed structural superposition of CAL1-CENP-A/H4 complex onto the crystal structure of nucleosome core particle (PDB: 2PYO) (Clapier et al., 2008). This revealed that CAL1 shields the CENP-A/H4 regions critical for nucleosome assembly at: i) the CENP-A/H4 tetramerisation interface, ii) the $\mathrm{H} 2 \mathrm{~A} / \mathrm{H} 2 \mathrm{~B}$ binding region and iii) the DNA-binding region (Figure 4). CENP-A/H4 tetramerisation is thought to be the very first step in the nucleosome assembly pathway, followed by the wrapping of DNA by the CENP-A/H4 heterotetramer and incorporation of $\mathrm{H} 2 \mathrm{~A} / \mathrm{H} 2 \mathrm{~B}$ heterodimers (Hammond et al., 2017). Thus, the CAL1 bound form of CENP-A/H4 cannot be incorporated into the nucleosome, inhibiting any unwarranted incorporation of CENP-A.

\section{CENP-C binds CAL1 via its C-terminal cupin domain}

We next aimed to understand the structural basis for the centromere targeting of the CAL1 bound pre-nucleosomal CENP-A/H4 heterodimer. Previous studies have shown that CAL1 and CENP-C can directly interact with each other through their C-terminal regions, CAL $1_{699-}$

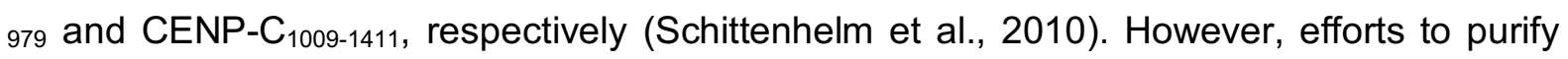
these recombinant proteins were not successful as they were sensitive to protease contaminants and so were unstable. Based on secondary structure prediction and sequence conservation analysis, we designed shorter constructs of CAL1 and CENP-C, CAL $1_{841-979}$ and CENP-C $_{1264-1411 .}$. The CENP-C fragment contains an evolutionarily conserved cupin domain. Reconstitution of CAL1-CENP-C complex using individually purified His-SUMO tagged CAL1 $_{841-979}$ (His-SUMO-CAL1 1841-979) and His-tagged CENP-C $_{1264-1411}$ (His-CENP-C 1264-1411) showed clear complex formation (Figure 5A): His-SUMO-CAL1 ${ }_{841-979}$ eluted at a volume of $10.38 \mathrm{ml}$, His-CENP-C ${ }_{1264-1411} 10.54 \mathrm{ml}$, whilst the complex eluted at $9.63 \mathrm{ml}$.

\section{Overall structure of CENP-C cupin domain}


A well conserved structural feature of CENP-C among different species is the presence of a C-terminal cupin domain. Previous structural characterisation of the cupin domain of Mif2p, the budding yeast orthologue of human CENP-C, showed that it forms a dimer (Cohen et al., 2008). Although CENP-Cs across species contain a C-terminal cupin domain, these appear to show striking amino acid variations. Pairwise sequence alignments of Drosophila CENP-C cupin domain against its budding yeast counterpart showed $11 \%$ sequence identity and $18 \%$ sequence identity against the human counterpart. Crystallisation trials carried out with CENP$\mathrm{C}_{1264-1411}$ alone and in complex with CAL1 produced diffraction quality crystals which diffracted X-rays to about $1.7 \AA$ and $2.4 \AA$, respectively (Table S1).

The CENP-C ${ }_{1264-1411}$ structure was determined by molecular replacement using the crystal structure of budding yeast Mif2p cupin domain (PDB: 2VPV) (Cohen et al., 2008). The twofold axis of the CENP-C ${ }_{1264-1411}$ dimer was aligned with the crystallographic two-fold axis. Consequently, just one molecule was present in the asymmetric unit (Figure 5B). As expected, CENP-C ${ }_{1264-1411}$ domain forms a cupin fold almost entirely made of $\beta$ strands forming a $\beta$-barrel with a helix preceding the cupin domain. The $\beta$ strands assemble into two $\beta$ sheets: a sixstranded ( $\beta 1-\beta 2-\beta 3-\beta 10-\beta 5-\beta 8)$ and a four-stranded $(\beta 4-\beta 9-\beta 6-\beta 7)$ (Figure $5 \mathrm{~B})$. The $\beta 1$ of the six-stranded $\beta$ sheet is connected to the preceding $\alpha 1$ (spanning aa residues 1276-1288) with a long loop (aa residues 1289-1313) containing two short $\alpha$ helical segments. Dimerisation of CENP-C cupin domain is mediated by a back-to-back arrangement of six stranded $\beta$-sheets. In this arrangement the loop connecting the $\mathrm{N}$-terminal $\alpha$ helix $(\alpha 1)$ to $\beta 1$ crosses-over to its dimeric counterpart resulting in a 'roof' like positioning of $\alpha$-helices on top of the $\beta$ barrels. The surface area buried at the dimerisation interface is $1706 \AA^{2}$ which is about $50 \%$ of the total solvent accessible surface area. The interactions stabilising the dimerisation are predominantly hydrophobic involving residues L1283, W1286, L1287, L1312, L1314, Y1325, Y 1335, M1407 and L1357 (Figure 5C). Among these residues, M1407 and L1357 are centrally located and juxtaposed within the hydrophobic core. This led us to hypothesise that these 
residues may be critical for the assembly of cupin dimer. To test this, we generated a mutant where M1407 and L1357 were mutated to glutamic acids (CENP-C $1264-1411$ M1407E/L1357E) and analysed their oligomeric structure by measuring the molecular weight using SEC-MALS (Figure 5D). While the measured molecular weight of CENP-C $1264-1411$ agreed with the calculated molecular weight of a dimer, the corresponding value for the His-CENP-C $1264-1411$ M1407E/L1357E revealed that it was a monomer (measured molecular weight 20.2kDa and calculated molecular weight 19.2kDa) (Figure 5D).

Structural comparison of $d m$ and budding yeast CENP-C cupin domains showed that although these domains share only weak similarity at the amino acid sequence level $(21 \%)$, the overall fold conferring the $\beta$ barrel structure is conserved. However, two loop regions ( $d m$ CENP-C 1324-1333 and 1368-1376) show striking conformational variation as compared with their equivalent regions in budding yeast CENP-C, Mif2p (Figure S5A).

\section{Structural basis for CAL1 recognition by CENP-C}

The structure of CENP- $\mathrm{C}_{1264-1411}$ bound to $\mathrm{CAL} 1_{841-979}$ was determined by molecular replacement using the $\mathrm{CENP}-\mathrm{C}_{1264-1411}$ structure reported here as a search model. The final model was refined to $R$ and $R_{\text {free }}$ factors of $23.0 \%$ and $26.9 \%$, respectively and included CENP-C residues 1303-1411 and CAL1 residues 890-913 (Figure 6A). This suggests that CAL1 residues preceding and following residues 890 and 913, respectively, are flexible and are not stabilised by CENP-C. While CAL1 residues $890-893$ form a $\beta$-strand, residues 894 913 form a highly basic $\alpha$ helix (calculated pl of 10.57). CENP-C binds CAL1 using a cradle shaped surface formed by loops L1, L2 and L3 and $\beta$-strands $\beta 1$ and $\beta 2$. The calculated electrostatic surface properties show that CAL1 binding involves a surface suitable for both electrostatic and hydrophobic interactions (Figure 6A). CAL1 residues 890-893, which form a $\beta$-strand interacts with $\beta 1$ of CENP-C cupin domain running parallel to it and as a consequence extend the $\beta$ sheet involved in cupin dimerisation. The CAL1 $\alpha$ helix consisting of residues 
894-913 makes several hydrophobic (involving L896, 1900, W904 and Y908) and electrostatic (R903 and K906) interactions with a complementary hydrophobic (involving residues Y1315, $\mathrm{V} 1317, \mathrm{Y} 1322$ and $\mathrm{F} 1323)$ and acidic (S1295, E1311 and N1326) region of the cradle shaped CENP-C surface (Figure 6). To evaluate the requirement of these interactions to stabilise CAL1-CENP-C binding, we mutated conserved CENP-C F1324 to Arg (F1324R) and CAL1 1900 to Arg and K907 and Y908 to Ala (1900R/K907A/Y908) and tested the ability of these mutants to bind wild type CAL1 and CENP-C, respectively, in separate SEC experiments

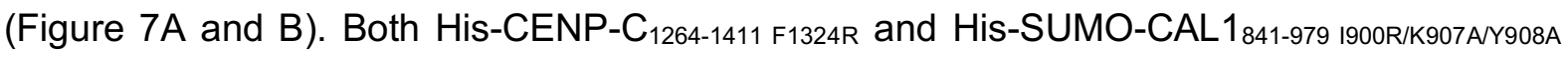
failed to interact with His-SUMO-CAL1 $1841-979$ and His-CENP-C ${ }_{1264-1411}$, respectively and hence eluted at their original elution volumes as compared with the elution volume of the CENP-CCAL1 complex.

We next evaluated the contribution of CENP-C and CAL1 residues identified here as critical for interaction in vitro in cultured cells where LacO arrays are integrated in one of the chromosome arms. Tethering GFP-Lacl-CENP-C recruited CAL1-V5 to the LacO array. However, the F1324R or the L1357E/M1407E mutation in CENP-C and I900R/K907A/Y908A mutations in CAL1 are both able to inhibit interaction and reduce co-localisation at the tethering site by 4 to 7 -fold (Figure 7D).

\section{Dimerisation of CENP-C cupin domain stabilises the CAL1 binding site}

Previously we showed that CENP-C dimerisation is required for CAL1 binding in cells (Roure et al., 2019). In the crystal structure presented here, the CAL1 binding site on CENP-C is in close proximity to the cupin dimerisation interface: the loop $L 1$ and $\beta$-strands $\beta 1, \beta 2$ and $\beta 3$ are all directly involved in stabilising the cupin dimer. This led us to hypothesise that the CAL1 binding site is stabilised in the right conformation by the dimerisation interface and hence disrupting the dimerisation interface might affect CAL1 binding. To test this, we evaluated using SEC the ability of His-CENP-C ${ }_{1264-1411}$ M1407E/L1357E, which we have shown here is not capable of forming a dimer (Figure 5D), to bind CAL1. His-SUMO-CAL1 841-979 $_{\text {was mixed with }}$ 
1.2 molar excess of His-CENP- $\mathrm{C}_{1264-1411}$ M1407E/L1357E and subjected to SEC analysis. HisSUMO-CAL1 $1_{841-979}$ and His-CENP-C $1264-1411$ M1407E/L1357E did not interact with each other and eluted separately at elution volumes $10.4 \mathrm{ml}$ and $11.6 \mathrm{ml}$, respectively (Figure 7C). Consistent with these in vitro data, GFP-Lacl-CENP-C tethered to the LacO site in U2OS cells recruited

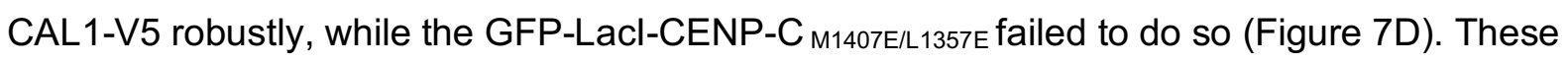
observations together demonstrate that the CENP-C dimerisation-mediated stabilisation of CAL1 binding site is an essential requirement for centromere targeting of CAL1.

\section{CENP-C cupin dimer binds just one CAL1}

Although CAL1 binding by CENP-C involves just a cupin monomer, only one of the two cupin monomers was observed to interact with CAL1 while the equivalent CAL1 binding site of the dimeric counterpart was empty in the crystal structure. We speculate that the other binding site might be sterically hindered by the remaining residues of CAL1 not seen in the crystal structure, thus not allowing a second monomer of CAL1 to bind. This agrees with our previous observation that CAL1 $1_{841-979}$ and CENP- C $_{1264-1411}$ form a 1:2 complex in solution as estimated using the mass spectrometry derived iBAC peptide ratio and SEC-MALS (Roure et al., 2019). To confirm the subunit stoichiometry of CAL1-CENP-C complex unambiguously, we measured the molecular mass of CAL1 ${ }_{841-979-C E N P-C_{1264-1411}}$ complex using Analytical Ultra Centrifugation (AUC) (Figure 7E). First, the individual components of the complex were characterised by both sedimentation velocity (SV) and sedimentation equilibrium (SE). The data from which (Figure S5B) demonstrate that CAL1 $1_{841-979}$ is monomeric with a very weak tendency to self-associate, while CENP- $\mathrm{C}_{1264-1411}$ is a dimer. Next, samples comprising a complex were analysed. The complex was formed by mixing an equimolar ratio of untagged CAL $_{841-979}$ and CENP-C ${ }_{1264-1411}$, subjecting it to SEC and using the peak containing the complex for AUC analysis. Both the mass and sedimentation coefficient are consistent with a 2:1 complex, but not with a 2:2 complex. Thus, the AUC together with the crystal structure show that CENP-C cupin dimer binds just one copy CAL1 at any given time. 


\section{Discussion}

Understanding the molecular details of how organisms maintain their centromere identity has been of great importance to biologists as loss of centromeres or establishment of new centromeres at non-centromeric locus (neocentromeres) results in genome instability, often leading to cell death. To maintain centromere identity defined by the enrichment of CENP-A containing nucleosome, the CENP-A-specific chaperone (HJURP in humans and Scm3 in yeast) escorts CENP-A until its incorporation into the centromeric chromatin (Pidoux et al., 2009, Foltz et al., 2009, Dunleavy et al., 2009). Correct spatio-temporal regulation of this process is achieved by the Mis18 complex in humans and fission yeast (Fujita et al., 2007, Hayashi et al., 2004, Foltz et al., 2009, Spiller et al., 2017, Pan et al., 2017, McKinley and Cheeseman, 2014). Despite the essential requirement of CENP-A deposition at centromeres, the pathways and the molecular players regulating this process show significant variations across organisms (Zasadzinska and Foltz, 2017). This suggests that these organisms have evolved to employ unique strategies to establish and maintain centromeric chromatin.

Drosophila is a remarkable model organism to study centromere inheritance as it lacks direct homologs of either HJURP and Scm3 or the Mis18 complex. Instead it maintains centromere identity using just CAL1. CAL1 does not share obvious sequence similarity with Scm3 or HJURP and does not appear to share common ancestry with these chaperones (Phansalkar et al., 2012, Rosin and Mellone, 2016, Sanchez-Pulido et al., 2009). Our structural analysis presented here shows that although CAL1 appears to have evolved independently of Scm3 and HJURP, it employs evolutionarily conserved structural principles to bind CENP-A. Recognition of CENP-A L1 and $\alpha 2$ by the N-terminal 50 aa residues of CAL1 is remarkably similar to that of Scm3 and HJURP. Despite this structural similarity, CAL1 is also distinctly dissimilar from Scm3 and HJURP as residues downstream of the N-terminal 50 aa wrap around CENP-A-H4 making additional contacts with CENP-A $\alpha 3$ and CAL1 itself. These interactions appear to be crucial for CENP-A deposition as the N-terminal 50 amino acids of 
CAL1 were not sufficient to recruit CENP-A to centromeres in cells (Chen et al., 2014). Notably, unlike the human CENP-A, the centromere targeting domain of Drosophila CENP-A includes $\alpha 3$ as L1 and $\alpha 2$ were not sufficient to target CENP-A (Roure et al., 2019).

The overall mode of CENP-A/H4 recognition by CAL1 appears to be novel as none of the available 'histone variant' - chaperone complex crystal structures shows a similar mode of 'histone variant' recognition: wrapping around CENP-A/H4 through multiple CENP-A and H4 contacts resulting in the shielding of CENP-A/H4 surfaces involved in CENP-A/H4 tetramerisation, DNA binding and $\mathrm{H} 2 \mathrm{~A} / \mathrm{H} 2 \mathrm{~B}$ binding - all critical for nucleosome assembly. This is in agreement with the observation that CAL1 cannot directly interact with the CENP-A nucleosome (Roure et al., 2019) and requires CENP-C to mediate the interaction with the centromeric chromatin.

In humans and fission yeast, the Mis18 complex is responsible for targeting the HJURP bound pre-nucleosomal CENP-A/H4 to the centromere by directly binding CENP-C (reviewed in Westhorpe and Straight, 2014, Zasadzinska and Foltz, 2017, Stellfox et al., 2012) but appears to have been lost during evolution in Drosophila. However, CAL1 seems to compensate for this loss by directly associating with CENP-C, which is present in all organisms with monocentric chromosomes (Drinnenberg et al., 2014). While there has been a suggestion that CENP-C cupin domain could be a dimer based on the crystal structure Mif2 $p$ cupin domain (Cohen et al., 2008), structural and functional roles of CENP-C cupin domain have remained unclear. Here we show that CAL1 associates with CENP-C by directly interacting with the cupin domain and this interaction is essential for CENP-C mediated recruitment in cells. Our structural analysis shows that the overall structure of Drosophila CENP-C cupin domain is similar to that of Mif2p, with striking differences in the mode of dimerisation. It is tempting to suggest that this variation is related to the ability of Drosophila CENP-C to bind CAL1 as the CAL1 binding interface of CENP-C is stabilised by dimerisation. Interestingly, although the CENP-C cupin dimer possess two CAL1 binding sites, it appears to accommodate just one 
CAL1 at a time due to steric hindrance limiting the accessibility of the second CAL1 site. This might have broader implications for the mechanism of CENP-C loading at centromeres (Roure et al., 2019). In the context of the full-length proteins, CAL1 can also oligomerise via its $\mathrm{N}$ terminus (Roure et al., 2019), leading to a scenario where a CENP-C bound CAL1 at the centromere might interact with a second CAL1 bringing another CENP-A/H4 dimer and CENPC to facilitate CENP-A/H4 tetramer incorporation and the recruitment of CENP-C to the newly formed CENP-A nucleosome (Figure 7F). This is consistent with CENP-C targeting being reliant on CAL1 and CENP-A (Goshima et al., 2007, Erhardt et al., 2008, Schittenhelm et al., 2010, Roure et al., 2019). These observations together with the proposed involvement of HJURP in de novo CENP-C recruitment in humans (Tachiwana et al., 2015) suggest that CAL1 is not only a CENP-A loader, but also a CENP-C loader.

In summary, our work demonstrates how Drosophila species elegantly compensates for the loss of HJURP or Scm3 and the Mis18 complex through CAL1, which by combining evolutionarily conserved and adaptive structural interactions escorts CENP-A/H4 to the centromere for its subsequent incorporation into the chromatin to maintain centromere identity. Moreover, this is the first study providing the structural basis for how the CENP-A deposition machinery is targeted to centromeres in any organism. Future structural studies on the Mis18 complex and its interaction with HJURP and CENP-C will shed insights into how apparently complex intermolecular interactions achieve the same objective in vertebrates and what are the species-specific functional requirements of this complexity.

\section{Acknowledgments}

We thank the staff of the Edinburgh Protein Production Facility, especially Martin Wear, for their help. Thanks to Atlanta Cook for critical reading of the manuscript. The Wellcome Trust generously supported this work through a Wellcome Trust Career Development Grant (095822) and a Senior Research Fellowship (202811) to AAJ, a Senior Research Fellowship 
(084229) to JR, a Senior Research Fellowship (103897) to PH, a Centre Core Grant (092076 and 203149) and an instrument grant (091020) to the Wellcome Trust Centre for Cell Biology, a Multi-User Equipment grant $101527 / Z / 13 / Z$ to the EPPF and a Wellcome-UoE ISSF award toward the procurement of SEC-MALS equipment for the EPPF. PH was further supported by a European Research Council Starting-Consolidator Grant (311674-BioSynCEN).

\section{Author Contributions}

$\mathrm{AAJ}$ and $\mathrm{PH}$ conceived the project. BM-P, VL, $\mathrm{PH}$ and $\mathrm{AAJ}$ designed experiments. BM-P,VL, OB and JZ performed experiments. JR provided expertise and feedback. BM-P and AAJ wrote the manuscript with input from all authors.

\section{Declaration of Interests}

All authors declare no competing interest.

\section{STAR*Methods}

\section{KEY RESOURCES TABLE}

\begin{tabular}{|c|c|c|}
\hline REAGENT or RESOURCE & SOURCE & IDENTIFIER \\
\hline \multicolumn{3}{|l|}{ Antibodies } \\
\hline & & \\
\hline & & \\
\hline & & \\
\hline \multicolumn{3}{|l|}{ Bacterial and Virus Strains } \\
\hline XL1 Blue & Aailent & Cat\#200249 \\
\hline Rosetta $(D E 3)$ & Novagen & Cat\#70954 \\
\hline BL21 (DE3) pLysS & Novagen & Cat\#69451 \\
\hline BL21 Gold (DE3) & Agilent & Cat\#230132 \\
\hline \multicolumn{3}{|l|}{ Biological Samples } \\
\hline & & \\
\hline & & \\
\hline & & \\
\hline \multicolumn{3}{|c|}{ Chemicals, Peptides, and Recombinant Proteins } \\
\hline Trypsin & Pierce & Cat\#90057 \\
\hline Sulfo-NHS & $\begin{array}{l}\text { Thermo Fisher } \\
\text { Scientific }\end{array}$ & Cat\#24510 \\
\hline
\end{tabular}




\begin{tabular}{|c|c|c|}
\hline EDC & $\begin{array}{l}\text { Thermo Fisher } \\
\text { Scientific }\end{array}$ & Cat\#22980 \\
\hline \multicolumn{3}{|l|}{ Critical Commercial Assays } \\
\hline & & \\
\hline & & \\
\hline & & \\
\hline \multicolumn{3}{|l|}{ Deposited Data } \\
\hline Crystal Structure of CAL1-CENP-A-H4 (form I) & This paper & \\
\hline Crystal Structure of CAL1-CENP-A-H4 (form II) & This paper & \\
\hline Crystal Structure of CENP-C & This paper & \\
\hline Crystal Structure of CAL1-CENP-C & This paper & \\
\hline Crosslinking Data & This paper & \\
\hline \multicolumn{3}{|l|}{ Experimental Models: Cell Lines } \\
\hline U2OS & $\begin{array}{l}\text { (Janicki et al., } \\
\text { 2004) }\end{array}$ & \\
\hline \multicolumn{3}{|l|}{ Experimental Models: Organisms/Strains } \\
\hline & & \\
\hline & & \\
\hline & & \\
\hline \multicolumn{3}{|l|}{ Oligonucleotides } \\
\hline $\begin{array}{l}\text { All oligonucleotides used in this study are listed } \\
\text { in Table S2 }\end{array}$ & This study & $\mathrm{N} / \mathrm{A}$ \\
\hline \multicolumn{3}{|l|}{ Recombinant DNA } \\
\hline pEC-K-3C-His CAL11-160 & This study & N/A \\
\hline pEC-K-3C-His CAL1 1-160 W22A/F29A & This study & N/A \\
\hline pEC-K-3C-His CAL11-160 W22R/F29R & This study & N/A \\
\hline pEC-K-3C-His CAL11-160 F43R & This study & $\mathrm{N} / \mathrm{A}$ \\
\hline pEC-K-3C-His CAL1 $1-50$ & This study & N/A \\
\hline 14S CAL1841-979 & This study & N/A \\
\hline 14S CAL1841-979 1900R/K907A/Y908A & This study & $\mathrm{N} / \mathrm{A}$ \\
\hline pET3a CENP-A $101-225$ & Karolin Luger & N/A \\
\hline pET3a CENP-A $101-225$ S154Q & This study & N/A \\
\hline 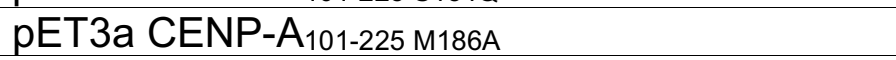 & This study & $\mathrm{N} / \mathrm{A}$ \\
\hline
\end{tabular}




\begin{tabular}{|c|c|c|}
\hline pET3a CENP-A $101-225$ Q190G & This study & N/A \\
\hline pET3a CENP-A $101-225$ S154Q/M186A & This study & N/A \\
\hline pET3a CENP-A A $_{101-225}$ S154Q/M186A/Q190G & This study & N/A \\
\hline pET3a CENP-A $A_{144-225}$ & This study & N/A \\
\hline pET22a H4 & Karolin Luger & N/A \\
\hline pEC-K-3C-His CENP-C $1264-1411$ & This study & N/A \\
\hline pEC-K-3C-His CENP-C 1264-1411 L1357E/M1407E & This study & N/A \\
\hline pEC-K-3C-His CENP-C $1264-1411$ F1324R & This study & N/A \\
\hline pMT CAL1 3Ha Hygro & $\begin{array}{l}\text { (Roure et al., } \\
2019)\end{array}$ & N/A \\
\hline pMT CAL1 w22A/F29A 3Ha Hygro & This study & N/A \\
\hline pMT CAL1 W22R/F29R 3Ha Hygro & This study & N/A \\
\hline pMT CAL1 F43R 3Ha Hygro & This study & N/A \\
\hline pMT CAL1 1900R/K907A/Y908A 3Ha Hygro & This study & N/A \\
\hline pN2 CMV CAL1 V5 & $\begin{array}{l}\text { (Roure et al., } \\
2019 \text { ) }\end{array}$ & N/A \\
\hline pN2 CMV CAL1 W22A/F29A V5 & This study & N/A \\
\hline pN2 CMV CAL1 W22R/F29R V5 & This study & N/A \\
\hline pN2 CMV CAL1 F43R V5 & This study & N/A \\
\hline pN2 CMV CAL1 1900R/K907A/Y908A V5 & This study & N/A \\
\hline pMT_GFP_Lacl CENP-C & $\begin{array}{l}\text { (Roure et al., } \\
\text { 2019) }\end{array}$ & N/A \\
\hline pMT_GFP_Lacl CENP-C L1357E/M1407E & This study & N/A \\
\hline pMT_GFP_Lacl CENP-C F1324R & This study & N/A \\
\hline pN2_CMV_GFP_Lacl CENP-C & $\begin{array}{l}\text { (Roure et al., } \\
\text { 2019) }\end{array}$ & N/A \\
\hline pN2_CMV_GFP_Lacl CENP-C L1357E/M1407E & This study & N/A \\
\hline pN2_CMV_GFP_Lacl CENP-C F1324R & This study & N/A \\
\hline pN2_CMV_CENP-A_GFP_Lacl & $\begin{array}{l}\text { (Roure et al., } \\
\text { 2019) }\end{array}$ & N/A \\
\hline pMT_3HA CENP-C & $\begin{array}{l}\text { (Roure et al., } \\
\text { 2019) }\end{array}$ & N/A \\
\hline pMT_3HA CENP-C L1357E/M1407E & This study & N/A \\
\hline pMT_3HA CENP-C ${ }_{F 1324 R}$ & This study & N/A \\
\hline pN2_CMV_3HA CENP-C & $\begin{array}{l}\text { (Roure et al., } \\
2019 \text { ) }\end{array}$ & N/A \\
\hline pN2_CMV_3HA CENP-C L1357E/M1407E & This study & N/A \\
\hline pN2_CMV_3HA CENP-C F1324R & This study & N/A \\
\hline \multicolumn{3}{|l|}{ Software and Algorithms } \\
\hline Clustalw2 v.2.1 & $\frac{\frac{\mathrm{https}: / / \text { doi.org/10.1 }}{\text { 093/bioinformatics/ }}}{\underline{\text { btm404 }}}$ & $\begin{array}{l}\text { http://www.clustal } \\
\text { org/clustal2/ }\end{array}$ \\
\hline COOT & $\begin{array}{l}\text { (Emsley and } \\
\text { Cowtan, 2004) }\end{array}$ & $\begin{array}{l}\frac{\mathrm{http}: / / \mathrm{www} 2 \cdot \mathrm{mrc}-}{\mathrm{Imb} \cdot \mathrm{cam} \cdot \mathrm{ac} \cdot \mathrm{uk} / \mathrm{p}} \\
\text { ersonal/pemsley/ } \\
\text { coot/ }\end{array}$ \\
\hline
\end{tabular}




\begin{tabular}{|c|c|c|}
\hline PyMOL & & $\begin{array}{l}\text { https://www.pym } \\
\text { ol.org }\end{array}$ \\
\hline Prism 7 & GraphPad & $\begin{array}{l}\text { https://www.grap } \\
\text { hpad.com/scientif } \\
\text { icsoftware/prism/ }\end{array}$ \\
\hline SEDFIT & Schuck (2000) & $\begin{array}{l}\text { http://www.analyt } \\
\text { icalultracentrifug } \\
\text { ation.com/default } \\
\text {.htm }\end{array}$ \\
\hline SEDNTERP & Hayes et al. (2012) & $\begin{array}{l}\text { http://bitcwiki.sr.u } \\
\text { nh.edu/index.php } \\
\text { /Main Page }\end{array}$ \\
\hline SEDPHAT & $\begin{array}{l}\text { Vistica et al. } \\
(2004)\end{array}$ & $\begin{array}{l}\text { http://www.analyt } \\
\text { icalultracentrifug } \\
\text { ation.com/sedph } \\
\text { at/index.htm }\end{array}$ \\
\hline SOMO & $\begin{array}{l}\text { Brookes and } \\
\text { Rocco (2018) }\end{array}$ & $\begin{array}{l}\text { http://somo.aucs } \\
\text { olutions.com/ }\end{array}$ \\
\hline \multicolumn{3}{|l|}{ Other } \\
\hline $\begin{array}{l}\text { cOmplete } \\
\text { Cocktail }\end{array}$ & Sigma-Aldrich & $\begin{array}{l}\text { Cat } \# 0505648900 \\
1\end{array}$ \\
\hline HisTrap ${ }^{\circledR}$ HP & GE Healthcare & Cat\#17-5248-02 \\
\hline HiTrap ${ }^{\circledR}$ Q HP & GE Healthcare & Cat\#17-1154-01 \\
\hline HiTrap ${ }^{\circledR}$ SP HP & GE Healthcare & Cat\#17-1152-01 \\
\hline HisPurTM Ni-NTA Resin & $\begin{array}{l}\text { Thermo Fisher } \\
\text { Scientific }\end{array}$ & Cat\#88222 \\
\hline Superdex 200 increase $10 / 300 \mathrm{GL}$ & GE Healthcare & Cat\#28990944 \\
\hline Superdex 75 increase 10/300 GL & GE Healthcare & Cat\#29148721 \\
\hline Phusion Ultra II & Agilent & Cat\#600670 \\
\hline T4 DNA Polymerase & NEB & Cat\#M0203L \\
\hline Phusion & NEB & Cat\#M0530L \\
\hline Bolt $^{\mathrm{TM}} 4-12 \%$ Bis-Tris Plus Gels, 12-well & Invitrogen & $\begin{array}{l}\text { Cat\#NW04122B } \\
\text { OX }\end{array}$ \\
\hline Bolt $^{\mathrm{TM}} 4-12 \%$ Bis-Tris Plus Gels, 15-well & Invitrogen & $\begin{array}{l}\text { Cat\#NW04125B } \\
\text { OX }\end{array}$ \\
\hline 20x MES Buffer & Invitrogen & Cat\#NP0002 \\
\hline Millex Syringe Filter & Millipore & $\begin{array}{l}\text { Cat\#SLHVM25N } \\
\text { S }\end{array}$ \\
\hline Crystal Gryphon robot & Art Robbins & N/A \\
\hline JCSG+ & $\begin{array}{l}\text { Molecular } \\
\text { Dimensions }\end{array}$ & Cat\#MD1-37 \\
\hline Structures Screen $1+2$ & $\begin{array}{l}\text { Molecular } \\
\text { Dimensions }\end{array}$ & Cat\#MD1-30 \\
\hline Viscotek SEC-MALS 20 & $\begin{array}{l}\text { Malvern } \\
\text { Instruments }\end{array}$ & N/A \\
\hline Viscotek RI Detector & $\begin{array}{l}\text { Malvern } \\
\text { Instruments }\end{array}$ & Cat\#VE3580 \\
\hline
\end{tabular}




\section{CONTACT FOR REAGENT AND RESOURCE SHARING}

Further information and requests for resources and reagents should be directed to and will be fulfilled by the Lead Contact, A. A. Jeyaprakash (Jeyaprakash.Arulanandam@ed.ac.uk).

\section{EXPERIMENTAL MODEL AND SUBJECT DETAILS}

\section{Bacterial Strains}

Histones were expressed using BL21 (DE3) pLysS, CAL1 using BL21 Gold (DE3) and CENPC using Rosetta (DE3) competent Escherichia coli.

\section{METHOD DETAILS}

\section{Plasmids}

Codon optimised Drosophila melanogaster CAL1 and CENP-C were produced as gBlocks (IDT) with additional end sequences to make them compatible with ligation independent cloning (LIC). CAL11-50, CAL11-160, CAL1841-979 and CENP-C ${ }_{1264-1411}$ were produced by either using gBlocks directly or sub-cloning required fragments by Phusion amplification. Inserts and vectors were processed with T4 DNA polymerase according to manual instructions. pET His6 Sumo TEV (14S Addgene plasmid \# 48291) was a gift from Scott Gradia. pEC-K-3C-His was a gift from Elena Conti. pET3a CENP-A $\mathrm{A}_{101-225}$ and pET22b H4 were kind gifts from Karolin Luger.

CAL1 1-160 mutants (W22A/F29A, W22R/F29R and F43R), CAL1 $1_{841-979}$ mutants (I900R/K907A/Y908A), CENP-A 101-225 mutants (S154Q, M186A, Q190G, S154Q/M186A and S154Q/M186A/Q190G) and CENP-C ${ }_{1264-1411}$ mutant (L1357E/M1407E, F1324R) were generated following the site-directed mutagenesis protocol using phusion ultra II (Table S2).

\section{Protein Production}

Purification of histones 
To purify from inclusion bodies, histones were expressed in E. coli BL21 (DE3) pLysS cells grown in $2 \mathrm{~L}$ of $\mathrm{LB}$ media at $37^{\circ} \mathrm{C}$ until O.D 0.6. Cells were induced with IPTG to a final concentration of $0.2 \mathrm{mM}$ at $37^{\circ} \mathrm{C}$ for $3-4$ hours before harvesting by centrifugation at $4000 \times \mathrm{g}$ for $10 \mathrm{~min}$. Pellets were resuspended in $50 \mathrm{mM}$ Tris- $\mathrm{HCl} \mathrm{pH}$ 8, $100 \mathrm{mM} \mathrm{NaCl}, 1 \mathrm{mM}$ EDTA, 1 $\mathrm{mM}$ benzamidine and $5 \mathrm{mM}$ BME and snap frozen in liquid nitrogen. After two rounds of freeze thaw cycles the cells were further lysed by sonication and any soluble proteins were separated by centrifugation at $22,000 \mathrm{rpm}$ for $1 \mathrm{~h}$ at $4^{\circ} \mathrm{C}$. The insoluble pellets were washed twice with $50 \mathrm{mM}$ Tris- $\mathrm{HCl} \mathrm{pH}$ 8, $100 \mathrm{mM} \mathrm{NaCl}, 1 \mathrm{mM}$ EDTA, $1 \mathrm{mM}$ benzamidine, $5 \mathrm{mM}$ ßME and 1\% triton then twice with $50 \mathrm{mM}$ Tris- $\mathrm{HCl} \mathrm{pH}$ 8, $100 \mathrm{mM} \mathrm{NaCl}, 1 \mathrm{mM}$ EDTA, $1 \mathrm{mM}$ benzamidine and $5 \mathrm{mM}$ ßME using a glass homogeniser and pelleting by centrifugation at 22,000 rpm for $10 \min$ at $4^{\circ} \mathrm{C}$ in between.

Pellets were then left to soak with $500 \mu$ l of DMSO for 15 min before resuspending in $20 \mathrm{mM}$ Tris- $\mathrm{HCl} \mathrm{pH}$ 7.5, $7 \mathrm{M}$ guanidine $\mathrm{HCl}, 10 \mathrm{mM}$ DTT. After brief sonication, samples were left rotating at RT for $2 \mathrm{~h}$, the unfolded protein was then recovered by centrifugation at RT for 20 $\min$ at $22,000 \mathrm{rpm}$.

Next the histone was dialysed twice for $2 \mathrm{~h}$ and once overnight against $500 \mathrm{ml}$ of a buffer containing $10 \mathrm{mM}$ Tris $\mathrm{pH} 8,100 \mathrm{mM} \mathrm{NaCl}, 7 \mathrm{M}$ urea, $1 \mathrm{mM}$ EDTA and $5 \mathrm{mM}$ BME. Proteins were then centrifuged at $4^{\circ} \mathrm{C}$ at $22,000 \mathrm{rpm}$ for $30 \mathrm{~min}$, before briefly sonicating then passing through a Millex syringe filter (Millipore). Proteins where then further purified using ion exchange in such a way that samples were passed first through a HiTrap ${ }^{\circledR}$ Q HP column (GE Healthcare) equilibrated with dialysis buffer, then a HiTrap ${ }^{\circledR}$ SP HP column. Protein bound to the HiTrap ${ }^{\circledR}$ SP HP was eluted using a gradient of $10 \mathrm{mM}$ Tris- $\mathrm{HCl} \mathrm{pH} 8,1 \mathrm{M} \mathrm{NaCl}, 7 \mathrm{M}$ urea, $1 \mathrm{mM}$ EDTA and $5 \mathrm{mM}$ ßME. After analysis by SDS-PAGE, appropriate fractions were pooled

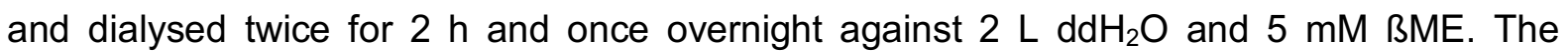


concentration of the histones was measured by Bradford assay and then proteins were lyophilised for storage.

\section{Purification of $\mathrm{N}$-term CAL1 proteins}

His-CAL1 1-160 and His-CAL1 1-50 were expressed using E. coli BL21 (DE3) Gold grown in 2XTY media and induced at $18^{\circ} \mathrm{C}$ using $0.3 \mathrm{mM}$ IPTG before being purified under native and denaturing conditions. Under native conditions pellets were resuspended in a buffer containing $20 \mathrm{mM}$ Tris- $\mathrm{HCl}$ ( $\mathrm{pH}$ 8.0), $100 \mathrm{mM} \mathrm{NaCl}, 35 \mathrm{mM}$ imidazole and $2 \mathrm{mM}$ ßME and supplemented with cOmplete -EDTA-free (Sigma) before lysing by sonication. Clarified lysates were applied onto a HisTrap ${ }^{\circledR} \mathrm{HP}$ column then washed with $60 \mathrm{CV}$ of lysis buffer, $20 \mathrm{CV}$ of $20 \mathrm{mM}$ Tris- $\mathrm{HCl}$ (pH 8.0), $1 \mathrm{M} \mathrm{NaCl}, 35 \mathrm{mM}$ imidazole, $50 \mathrm{mM} \mathrm{KCl}, 10 \mathrm{mM} \mathrm{MgCl}, 2 \mathrm{mM}$ ATP and $2 \mathrm{mM}$ ßME then $10 \mathrm{CV}$ lysis buffer. Proteins were then eluted in $20 \mathrm{mM}$ Tris- $\mathrm{HCl} \mathrm{pH} 8.0,100 \mathrm{mM} \mathrm{NaCl}$, $500 \mathrm{mM}$ imidazole and $2 \mathrm{mM}$ ßME.

For denatured proteins, pellets were suspended in $2 \mathrm{ml} / \mathrm{g}$ of wet pellet of $20 \mathrm{mM}$ Tris- $\mathrm{HCl} \mathrm{pH}$ 8.0, $500 \mathrm{mM} \mathrm{NaCl}, 25 \mathrm{mM}$ imidazole, $7 \mathrm{M}$ urea and $2 \mathrm{mM} \mathrm{BME}$, and incubated for $1 \mathrm{~h}$ at $4^{\circ} \mathrm{C}$ with rotation. The suspension was then sonicated to shear DNA before clarifying by centrifugation. Lysate was then incubated with $10 \mathrm{ml}$ of HisPurTM Ni-NTA resin (Thermo Fisher Scientific) overnight, before washing with $60 \mathrm{CV}$ of buffer, $20 \mathrm{CV}$ of $20 \mathrm{mM}$ Tris- $\mathrm{HCl}(\mathrm{pH} 8.0)$, $1 \mathrm{M} \mathrm{NaCl}, 25 \mathrm{mM}$ imidazole, $7 \mathrm{M}$ urea and $2 \mathrm{mM} \mathrm{BME}, 10 \mathrm{CV}$ of $500 \mathrm{mM} \mathrm{NaCl}$ buffer before eluting with $20 \mathrm{mM}$ Tris- $\mathrm{HCl}(\mathrm{pH}$ 8.0), $500 \mathrm{mM} \mathrm{NaCl}, 500 \mathrm{mM}$ imidazole, $7 \mathrm{M}$ guanidine $\mathrm{HCl}$ and $2 \mathrm{mM}$ ßME.

\section{Protein refolding}

To refold histones with and without CAL1, histones were resuspended in $20 \mathrm{mM}$ Tris- $\mathrm{HCl} \mathrm{pH}$ 7.5, $7 \mathrm{M}$ guanidine $\mathrm{HCl}$ and $2 \mathrm{mM} \mathrm{BME}$ and mixed with equimolar amounts of proteins needed. Proteins were then dialysed for $2 \mathrm{~h}$ at $4^{\circ} \mathrm{C}$ against $200 \mathrm{ml}$ of $20 \mathrm{mM}$ Tris- $\mathrm{HCl} \mathrm{pH} \mathrm{7.5,} 7 \mathrm{M}$ 
guanidine $\mathrm{HCl}$ and $2 \mathrm{mM} ß M E$, then $2 \mathrm{~L}$ of $10 \mathrm{mM}$ Tris- $\mathrm{HCl} \mathrm{pH}$ 7.5, $2 \mathrm{M} \mathrm{NaCl}, 1 \mathrm{mM}$ EDTA and $5 \mathrm{mM}$ ßME was slowly added overnight using a peristaltic pump. If needed, refolded protein was further dialysed against a lower salt concentration solvent; if not, complexes were concentrated and purified by SEC using either a Superdex 200 increase 10/300 GL or Superdex 75 increase 10/300 GL column (GE Healthcare).

\section{Purification of CENP-C}

His-CENP-C ${ }_{1264-1411}$ was expressed in Rosetta cells using 2 XTY and induced at $18^{\circ} \mathrm{C}$ overnight using $0.3 \mathrm{mM}$ IPTG. Pellets were resuspended in $20 \mathrm{mM}$ Tris- $\mathrm{HCl} \mathrm{pH} 8.0,100 \mathrm{mM} \mathrm{NaCl}, 35$ $\mathrm{mM}$ imidazole and $2 \mathrm{mM}$ BME and supplemented with $1 \mathrm{mM} \mathrm{PMSF}$ and cOmplete-EDTA-free before being lysed by sonication. Clarified lysates were applied to a $5 \mathrm{ml}$ HisTrap ${ }^{\circledR} \mathrm{HP}$ column and washed with $80 \mathrm{CV}$ of lysis buffer. Protein was eluted using $20 \mathrm{mM}$ Tris- $\mathrm{HCl}$ pH 8.0, 100 $\mathrm{mM} \mathrm{NaCl}, 500 \mathrm{mM}$ imidazole and $2 \mathrm{mM} \mathrm{BME}$ and fractions containing protein were dialysed overnight against $20 \mathrm{mM}$ Tris- $\mathrm{HCl} \mathrm{pH} 8.0,500 \mathrm{mM} \mathrm{NaCl}$, and $2 \mathrm{mM}$ DTT. Tags were removed by incubation with 3C O/N. Proteins were purified by SEC using either a Superdex 75 10/300 GL or Superdex 75 increase 10/300 GL column (GE Healthcare).

\section{Purification of C-term CAL1 protein}

His-SUMO-CAL1 $1_{841-979}$ was expressed in BL21 (DE3) Gold in LB and induced at $18^{\circ} \mathrm{C}$ overnight using $0.3 \mathrm{mM}$ IPTG. Purification was performed as for His-CENP- $\mathrm{C}_{1264-1411}$ with an additional ion-exchange step. Dialysed protein was applied to a HiTrap ${ }^{\circledR} \mathrm{Q}$ HP column and eluted with a gradient of $10-60 \% 20 \mathrm{mM}$ Tris- $\mathrm{HCl}(\mathrm{pH} 8.0), 1 \mathrm{M} \mathrm{NaCl}$, and $2 \mathrm{mM}$ DTT over 10 CV. Tags were removed by incubation with TEV overnight followed by a reverse affinity step. Proteins were purified by SEC using either a Superdex 200 increase 10/300 GL or Superdex 75 increase 10/300 GL column (GE Healthcare).

\section{Crystal Structure Determination and Analysis}




\section{Crystallisation}

Crystallisation trials were preformed using a nanoliter crystal Gryphon robot (Art Robbins) and grown by vapor diffusion methods. For CAL $1_{1-160}-\mathrm{CENP}-\mathrm{A}_{101-225}-\mathrm{H} 4,27 \mathrm{mg} / \mathrm{ml}$ of complex in a buffer of $20 \mathrm{mM}$ Tris- $\mathrm{HCl}$ pH8.0, $1 \mathrm{M} \mathrm{NaCl}$ and $5 \mathrm{mM}$ DTT was used with Structure Screen 1 +2 (Molecular Dimensions) at $18^{\circ} \mathrm{C}$. Crystals were obtained after about a year in $\mathrm{G} 1-0.01$ M Cobalt (II) chloride hexahydrate, $0.1 \mathrm{M}$ MES pH 6.5 and $1.8 \mathrm{M}$ ammonium sulphate. For CAL11-160-CENP-A ${ }_{144-225}-\mathrm{H} 4$, protein in $20 \mathrm{mM}$ Tris- $\mathrm{HCl} \mathrm{pH} 8.0,1 \mathrm{M} \mathrm{NaCl}$ and $2 \mathrm{mM}$ DTT was concentrated to $17 \mathrm{mg} / \mathrm{ml}$ and used with Structures $1+2$ at $18^{\circ} \mathrm{C}$. Crystals were obtained in C11, $0.2 \mathrm{M}$ lithium sulfate, $0.1 \mathrm{M}$ Tris $\mathrm{pH} 8.5$ and $30 \%$ PEG 4000. An optimisation screen was set up in a 24 well format, using half the original concentrations of protein. Tris- $\mathrm{HCl} \mathrm{pH} 8.5$ was kept at $0.1 \mathrm{M}$ whilst concentrations of lithium sulfate varied from 0.1-0.3 M and PEG 4000 varied from $24-34 \%$.

Cleaved CENP-C ${ }_{1264-1411}$ was screened at $15 \mathrm{mg} / \mathrm{ml}$ in $20 \mathrm{mM}$ Tris- $\mathrm{HCl}$ pH 8.0, $500 \mathrm{mM} \mathrm{NaCl}$ and $2 \mathrm{mM}$ DTT against several commercial and homemade screens at $18^{\circ} \mathrm{C}$. Crystals were obtained in around $13 \%$ of all conditions tested. His-CENP- C $_{1264-1411-C A L} 1_{841-979}$ complex was made in $20 \mathrm{mM}$ Tris- $\mathrm{HCl} \mathrm{pH} 8.0,100 \mathrm{mM} \mathrm{NaCl}$ and $2 \mathrm{mM}$ DTT and used with Structure $1+2$ and JCSG+ (Molecular Dimensions) at $15 \mathrm{mg} / \mathrm{ml}$ at $4^{\circ} \mathrm{C}$. Crystals were briefly transferred to a cryoprotectant solution (either oil or the mother liquor supplemented with 40\% peg 3350) before directly flash cooled in liquid nitrogen and analysed on beamline i03 and i04-1at the Diamond Light Source (Didcot, UK).

\section{Data Collection and Crystal Structure Determination}

Diffraction data were collected on beamlines i03 (CAL1 1-160-CENP-A/H4 Form I, CENP-C ${ }_{1264-}$

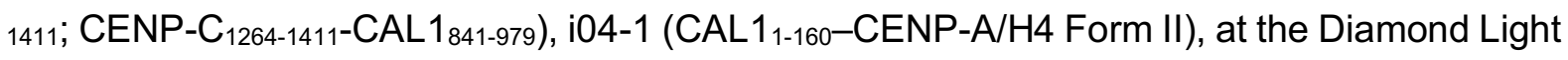
Source (Didcot, UK). Data were processed using the software pipeline available at Diamond Light Source that relies on XDS, CCP4, CCTBX, autoPROC and staraniso (Winter and 
McAuley, 2011, Kabsch, 2010, Grosse-Kunstleve et al., 2002, Winn et al., 2011, Vonrhein et al., 2011, Tickle et al., 2018). CAL11-160-CENP-A/H4 (Form I and II), CENP-C ${ }_{1264-1411}$, and CENP-C ${ }_{1264-1411-C A L} 1_{841-979}$ structures were determined by molecular replacement with the program PHASER (McCoy et al., 2007) using the coordinates of $d m \mathrm{H} 3 / \mathrm{H} 4$ heterodimer deduced from the structure of $d m$ nucleosome core particle, PDB: 2PYO (Clapier et al., 2008)

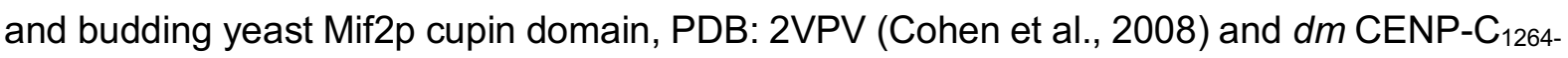
1411 determined here, respectively. Structures were refined using the PHENIX suite of programs (Adams et al., 2010). CAL1 1-160-CENP-A/H4 Form II was refined using PHENIXRosetta (DiMaio et al., 2013). Model building and structural superpositions were done using COOT (Emsley and Cowtan, 2004). Figures were prepared using PyMOL (http://www.pymol.org). Data collection, phasing and refinement statistics are shown in Table S1.

\section{Ni-NTA interaction trials}

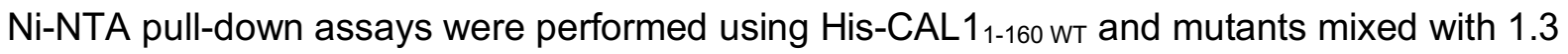
times molar excess of CENP-A $101-225-\mathrm{H} 4$ and made up to $100 \mu \mathrm{l}$ with $20 \mathrm{mM}$ Tris- $\mathrm{HCl} \mathrm{pH} 8.0$, $2 \mathrm{M} \mathrm{NaCl}, 10 \%$ glycerol, 0.5\% NP40, $35 \mathrm{mM}$ imidazole and $2 \mathrm{mM}$ BME. $90 \mu \mathrm{l}$ was incubated with $60 \mu$ l of HisPurTM Ni-NTA resin slurry that had been washed with $\mathrm{ddH}_{2} \mathrm{O}$ and buffer for 30 $\min$ at $4^{\circ} \mathrm{C}$. Beads were then washed four times with $1 \mathrm{ml}$ of buffer, then twice with $1 \mathrm{ml}$ of 20 $\mathrm{mM}$ Tris- $\mathrm{HCl} \mathrm{pH}$ 8.0, $500 \mathrm{mM} \mathrm{NaCl}, 35 \mathrm{mM}$ imidazole and $2 \mathrm{mM} \mathrm{BME}$ and eluted by boiling in SDS-PAGE loading dye before being separated on a Bolt ${ }^{\mathrm{TM}} 4-12 \%$ Bis-Tris Plus gel run at 180 V for $1 \mathrm{~h}$ in MES buffer.

\section{SEC-MALS}

Size-exclusion chromatography (ÄKTA-Micro ${ }^{\mathrm{TM}}$, GE Healthcare) coupled to UV, static light scattering and refractive index detection (Viscotek SEC-MALS 20 and Viscotek RI Detector 
VE3580; Malvern Instruments) was used to determine the molecular mass of proteins and protein complexes in solution. Injections of $100 \mu \mathrm{l}$ of $1-5 \mathrm{mg} / \mathrm{ml}$ material were used.

For His-CAL1 11-160-CENP-A $101-225-\mathrm{H} 4\left(\partial \mathrm{A}_{280 \mathrm{~nm}} / \partial \mathrm{c}=0.67\right.$ AU.ml.mg-1 $)$, His-CAL11-160-CENP-A $144-$ ${ }_{225} \mathrm{H} 4\left(\partial \mathrm{A}_{280 \mathrm{~nm}} / \partial \mathrm{c}=0.75 \mathrm{AU} \cdot \mathrm{ml} \cdot \mathrm{mg}^{-1}\right)$ and His-CAL11-50-CENP-A ${ }_{101-225}-\mathrm{H} 4\left(\partial \mathrm{A}_{280 \mathrm{~nm}} / \partial \mathrm{c}=0.55\right.$ AU.ml.mg ${ }^{-1}$ ) were run at RT on a Superdex 200 increase 10/300 GL size exclusion column pre-equilibrated in $50 \mathrm{mM}$ HEPES $\mathrm{pH} 8.0,2 \mathrm{M} \mathrm{NaCl}$ and $1 \mathrm{mM} \mathrm{TCEP}$ at $22^{\circ} \mathrm{C}$ with a flow rate of $0.5 \mathrm{ml} / \mathrm{min}$. His-CENP-C $1264-1411$ L1357E/M1407E $\left(\partial \mathrm{A}_{280 \mathrm{~nm}} / \partial \mathrm{c}=0.75 \mathrm{AU} \cdot \mathrm{ml}_{\mathrm{mg}}{ }^{-1}\right)$ was run on a Superdex 200 increase 10/300 GL size exclusion column pre-equilibrated in 50 mM HEPES $\mathrm{pH} 8.0,300 \mathrm{mM} \mathrm{NaCl}$ and $1 \mathrm{mM}$ TCEP at $22^{\circ} \mathrm{C}$ with a flow rate of $0.5 \mathrm{ml} / \mathrm{min}$. CENP-C ${ }_{1264-1411}$ $\left(\partial \mathrm{A}_{280 \mathrm{~nm}} / \partial \mathrm{c}=0.84 \mathrm{AU} \cdot \mathrm{ml} \cdot \mathrm{mg}^{-1}\right)$ was run at $4^{\circ} \mathrm{C}$ on a Superdex 75 increase $10 / 300 \mathrm{GL}$ size exclusion column pre-equilibrated in $50 \mathrm{mM}$ HEPES $\mathrm{pH} 8.0,100 \mathrm{mM} \mathrm{NaCl}$ and $1 \mathrm{mM}$ TCEP. Light scattering, refractive index $(\mathrm{RI})$ and $\mathrm{A}_{280 \mathrm{~nm}}$ were analysed by a homo-polymer model (OmniSEC software, v5.02; Malvern Instruments) using the parameters stated for each protein, $\partial \mathrm{n} / \partial \mathrm{c}=0.185 \mathrm{ml} \cdot \mathrm{g}^{-1}$ and buffer $\mathrm{RI}$ value of 1.335 . The mean standard error in the mass accuracy determined for a range of protein-protein complexes spanning the mass range of $6-600 \mathrm{kDa}$ is $\pm 1.9 \%$.

\section{Cross-Linking Mass Spectrometry (CLMS)}

Crosslinking was performed on gel filtered complexes dialysied into PBS. $30 \mu \mathrm{g}$ of zero-length crosslinkers EDC (Thermo Fisher Scientific) and $66 \mu \mathrm{g}$ sulfo-NHS (Thermo Fisher Scientific) were used to crosslink $10 \mu \mathrm{g}$ of protein for $1.5 \mathrm{~h}$ at RT. The reactions were quenched with 100 $\mathrm{mM}$ Tris- $\mathrm{HCl}$ before separation on Bolt ${ }^{\mathrm{TM}} 4-12 \%$ Bis-Tris plus gels (Invitrogen). The bands excised and proteins were reduced with $10 \mathrm{mM}$ DTT for $30 \mathrm{~min}$ at room temperature before being alkylated with $55 \mathrm{mM}$ iodoacetamide for $20 \mathrm{~min}$ in the dark at room temperature. Proteins were digested with $13 \mathrm{ng} / \mu \mathrm{l}$ trypsin (Pierce) overnight at $37^{\circ} \mathrm{C}$. The digested peptides were loaded onto C18-Stage-tips (Rappsilber et al., 2007) for LC-MS/MS analysis. LC-MS/MS analysis was performed using an Orbitrap Fusion Lumos (Thermo Fisher Scientific) with a 
"high/high" acquisition strategy. The peptide separation was carried out on an EASY-Spray column (50 cm $\times 75 \mu \mathrm{m}$ i.d., PepMap C18, $2 \mu \mathrm{m}$ particles, $100 \AA$ pore size, Thermo Fisher Scientific). Mobile phase A consisted of water and $0.1 \% \mathrm{v} / \mathrm{v}$ formic acid. Mobile phase $\mathrm{B}$ consisted of $80 \% \mathrm{v} / \mathrm{v}$ acetonitrile and $0.1 \% \mathrm{v} / \mathrm{v}$ formic acid. Peptides were loaded at a flow rate of $0.3 \mu \mathrm{l} / \mathrm{min}$ and eluted at $0.2 \mu \mathrm{l} / \mathrm{min}$ using a linear gradient going from $2 \%$ mobile phase $B$ to $40 \%$ mobile phase B over 109 followed by a linear increase from $40 \%$ to $95 \%$ mobile phase B in $11 \mathrm{~min}$. The eluted peptides were directly introduced into the mass spectrometer. MS data were acquired in the data-dependent mode with a $3 \mathrm{~s}$ acquisition cycle. Precursor spectra were recorded in the Orbitrap with a resolution of 120,000 . The ions with a precursor charge state between $3+$ and $8+$ were isolated with a window size of $1.6 \mathrm{~m} / \mathrm{z}$ and fragmented using high-energy collision dissociation (HCD) with a collision energy of 30 . The fragmentation spectra were recorded in the Orbitrap with a resolution of 15,000. Dynamic exclusion was enabled with single repeat count and $60 \mathrm{~s}$ exclusion duration. The mass spectrometric raw files were processed into peak lists using ProteoWizard (version 3.0.6618) (Kessner et al., 2008), and cross-linked peptides were matched to spectra using Xi software (version 1.6.745) (Mendes et al., 2018) with in-search assignment of monoisotopic peaks (Lenz et al., 2018). Search parameters were MS accuracy, 3 ppm; MS/MS accuracy, 10ppm; enzyme, trypsin; cross-linker, EDC; max missed cleavages, 4; missing mono-isotopic peaks, 2; fixed modification, carbamidomethylation on cysteine; variable modifications, oxidation on methionine; fragments, $b$ and $y$ ions with loss of $\mathrm{H} 2 \mathrm{O}, \mathrm{NH} 3$ and $\mathrm{CH} 3 \mathrm{SOH}$.

\section{Cell culture and transfections}

U2OS cells containing 200 copies of an array of 256 tandem repeats of the 17 bp LacO sequence on chromosome 1 (gift from B.E. Black, University of Pennsylvania, Philadelphia; (Janicki et al., 2004)) were grown in DMEM supplemented with 10\% FBS and 1\% penicillinstreptomycin at $37^{\circ} \mathrm{C}$ in a $5 \% \mathrm{CO}_{2}$ incubator. Cells were seeded in $10 \mathrm{~cm}$ dishes, a day prior to transfection at a density of $2.5 \times 10^{6}$ cells per well. Transfections were performed with Lipofectamine 3000 (Life Technologies) according to the manufacturer's instructions, using 15 
$\mu \mathrm{g}$ of plasmid DNA and Opti-MEM I reduced serum medium (Life Technologies). Next day, cells were washed once with 1xDPBS, trypsinised, counted and re-plated on poly-lysine coated coverslips in 6 well plates at a density of $10^{6}$ cells per well. Downstream experiments were performed three days post-transfection.

\section{Immunofluorescence}

Cells were washed once in PBS and then fixed with 3.7\% formaldehyde in $0.1 \%$ Triton X-100 in 1 XPBS (PBST) for 8 min at RT. Following fixation, the slides were washed once in PBST and then blocked in Image-iT® FX signal enhancer in a humidified chamber at RT for at least $30 \mathrm{~min}$. All antibodies were incubated in a $1: 1 \mathrm{mix}$ of PBST and $10 \%$ normal goat serum (Life Technologies) overnight at $4^{\circ} \mathrm{C}$ in a humidified chamber and were used in 1:100 dilution unless otherwise stated: myc (Abcam-ab9106), V5 (Invitrogen-R96025), HA (clone 3F10; E. Kremmer, 1:20). Secondary antibodies coupled to Alexa Fluor 555 and 647 (Invitrogen) were used at 1:100 dilutions. Counterstaining of DNA was performed with DAPI $(5 \mu \mathrm{g} / \mathrm{ml})$ and coverslips were mounted on the slides with $30 \mu \mathrm{l}$ of SlowFade ${ }^{\circledR}$ Gold antifade reagent (Life technologies)

\section{Microscopy and image analysis}

All immunofluorescence images were taken as 50 z-stacks of $0.2 \mu \mathrm{m}$ increments, using a $100 \mathrm{x}$ oil immersion objective on a Deltavision RT Elite Microscope and a CoolSNAP HQ Monochrome camera. All images were deconvolved using the aggressive deconvolution mode in SoftWorx Explorer Suite (Applied Precision) and are shown as quick projections of maximum intensity.

The mean fluorescence intensity of the protein of interest was measured at the LacO spot, and then the mean fluorescence intensity in the nucleus (background) was subtracted from this value. 25-50 cells were analysed per biological replicate and a minimum of three independent biological replicates were quantified per experiment. 


\section{Analytical ultracentrifugation (AUC)}

Sedimentation velocity (SV) and sedimentation equilibrium (SE) experiments were performed using a Beckman Coulter XL-I analytical ultracentrifuge equipped with an An-50 Ti eight-hole rotor. Depending on their concentration, samples were loaded into 12 (low concentration) or $3 \mathrm{~mm}$ (high concentration) pathlength charcoal-filled epon double-sector centrepieces, sandwiched between two sapphire windows. For SV, samples were equilibrated at $4^{\circ} \mathrm{C}$ in vacuum for $6 \mathrm{~h}$ before running at $49 \mathrm{k} \mathrm{rpm}$. For SE, data were recorded at $26 \mathrm{k} \mathrm{rpm}$. The laser delay, brightness and contrast were pre-adjusted at $3 \mathrm{k}$ rpm to acquire the best quality interference fringes. Data were collected using Rayleigh interference and absorbance optics recording radial intensity or absorbance at $280 \mathrm{~nm}$. For SV, data were recorded between radial positions of 5.65 and $7.25 \mathrm{~cm}$, with a radial resolution of $0.005 \mathrm{~cm}$ and a time interval of 7 minutes, and analysed with the program SEDFIT (Schuck, 2000) using a continuous c(s) model. For SE data were recorded between radial positions of 6.00 and $7.25 \mathrm{~cm}$, with a radial resolution of $0.001 \mathrm{~cm}$ and a time interval of $3 \mathrm{~h}$ (until successive scans overlaid satisfactorily), and analysed with the program SEDPHAT (Vistica et al., 2004) using species analysis. The partial specific volume, buffer density and viscosity were calculated using SEDNTERP (Hayes et al., 2012). Sedimentation coefficients were computed from atomic coordinate models using SOMO (Brookes and Rocco, 2018).

\section{DATA AND SOFTWARE AVAILABILITY}

The accession numbers for the coordinates and structure factors reported in this paper are PDB: $x x x x-C A L 1_{1-160}-C E N P-A / H 4$ form I, xxxx-CAL11-160-CENP-A/H4 form II, xxxx-CENP$\mathrm{C}_{1264-1411}$ and $\mathrm{xxxx}-\mathrm{CENP}_{1264-1411-C A L}$ 1 $_{841-979}$. Crosslink date is deposited in y. 


\section{Figure Legends}

A

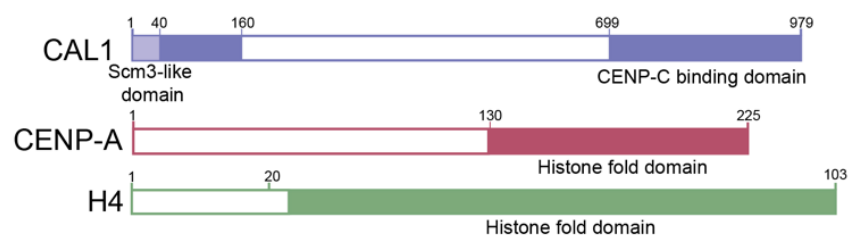

B

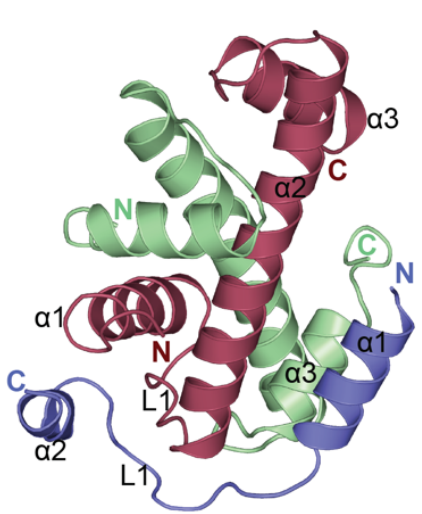

CAL1 - CENP-A/H4

(Crystal form I)

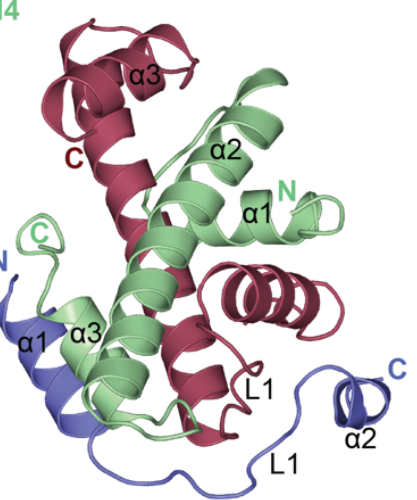

C
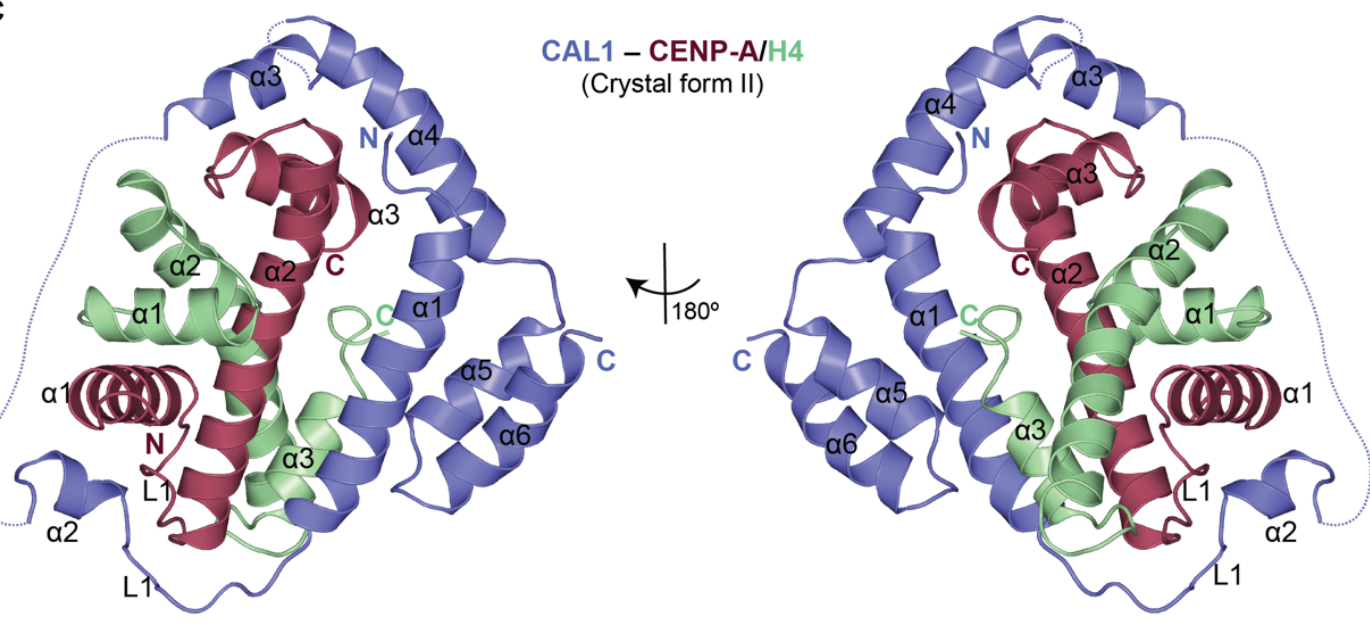

Figure 1 - N-terminal 160 amino acids of CAL1 wrap around CENP-A/H4 heterodimer to form a hetero-trimeric assembly

A - Schematic representation of structural features of CAL1, CENP-A and H4. Filled boxes represent folded domains.

B - Overall structure of His-CAL1 ${ }_{1-160}-C_{E N P}-A_{101-225}-\mathrm{H} 4$ (crystal form I). CAL1 is shown in blue, CENP-A in maroon and $\mathrm{H} 4$ in green. 
bioRxiv preprint doi: https://doi.org/10.1101/723213; this version posted August 2, 2019. The copyright holder for this preprint (which was

not certified by peer review) is the author/funder, who has granted bioRxiv a license to display the preprint in perpetuity. It is made available under aCC-BY-NC-ND 4.0 International license.

C - Overall structure of His-CAL1 ${ }_{1-160}-C_{E N P}-A_{144-225}-\mathrm{H} 4$ (crystal form II). CAL1 is shown in blue, CENP-A in maroon and H4 in green.

See also Figures S1-S4 
A

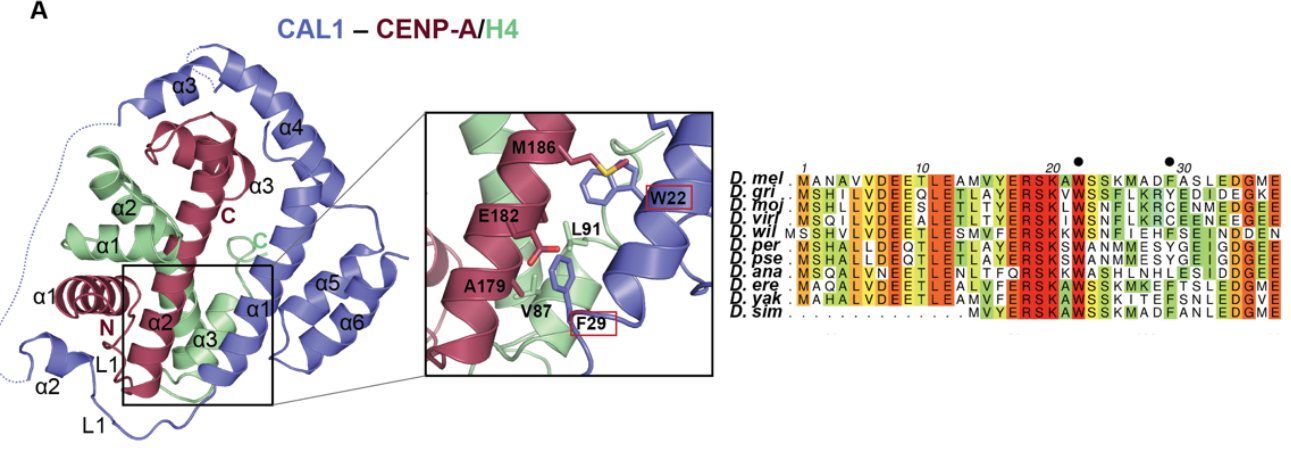

B SEC MALS His-CAL1 $1_{1-50}-$ CENP-A $_{101-225}-\mathrm{H} 4$

C
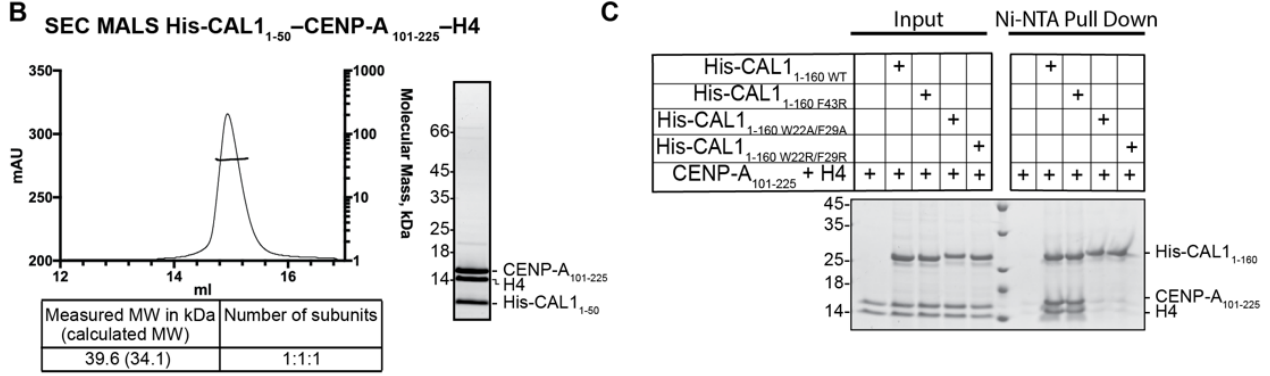

D
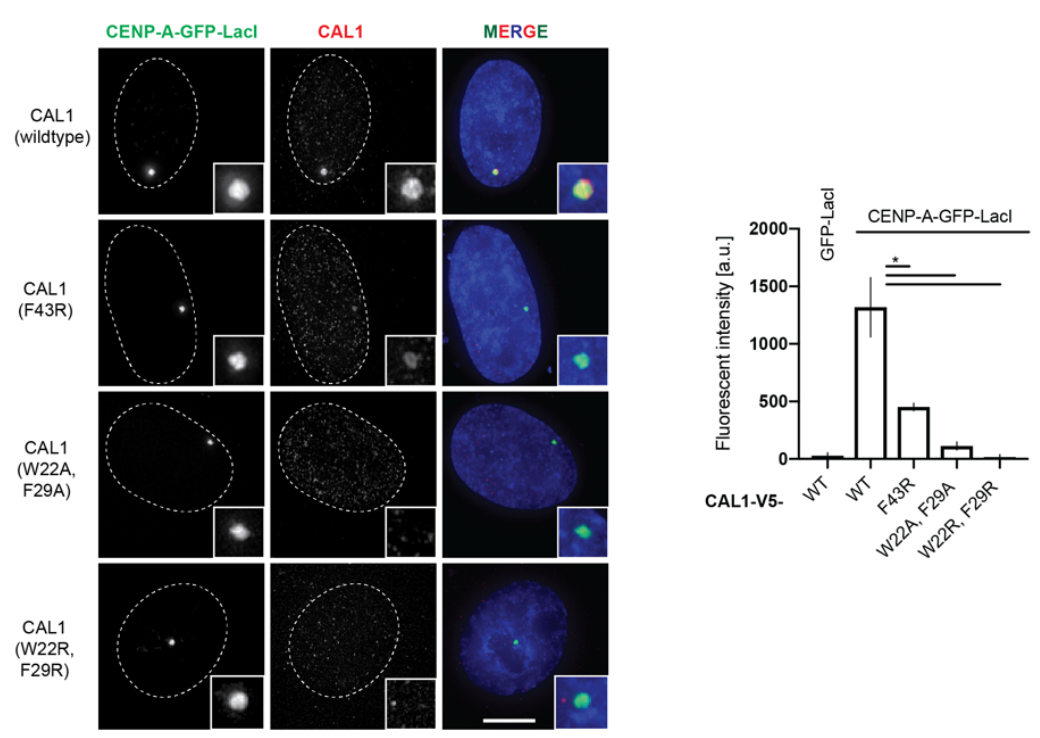

Figure 2 - Hydrophobic interactions between CAL1 $\alpha 1$ and CENP-A $\alpha 1$ are critical for

\section{CENP-A/H4 binding}

A - Crystal structure of His-CAL1 $1_{1-160}-C_{E N P}-\mathrm{A}_{144-225}-\mathrm{H} 4$ highlighting residues involved in electrostatic and hydrophobic interactions. CAL1 is shown in blue, CENP-A in maroon and H4 in green. Alignment performed with MUSCLE (Madeira et al., 2019) showing conservations of CAL1 homologues in different fly species. Numbers correspond to D. mel. D. melanogaster (D. mel), D. grimshawi (D. gri), D. mojavensis (D. moj), D. virilis (D. viri), D. willistoni (D. wil), 
D. persimilis (D. per), D. pseudoobscura pseudoobscura (D. pse), D. ananassae (D. ana), D. $\operatorname{erecta}(D$. ere), D. yakuba (D. yak) and D. simulans (D. sim).

B - SEC-MALS of His-CAL1 1-50-CENP-A ${ }_{101-225}-\mathrm{H} 4$. Absorption at $280 \mathrm{~nm}$ (mAU, left y-axis) and molecular mass ( $\mathrm{kDa}$, right $\mathrm{y}$-axis) are plotted against elution volume ( $\mathrm{ml}, \mathrm{x}$-axis). Measured molecular weight (MW) and the calculated subunit stoichiometry based on the predicted MW of different subunit compositions. Samples run on a Superdex 200 increase in $50 \mathrm{mM}$ HEPES pH8.0, $2 \mathrm{M} \mathrm{NaCl}$ and $1 \mathrm{mM}$ TCEP.

C - Ni-NTA pull-down of His-CAL1 1-160 wt and indicated mutants with CENP-A $101-225-H 4$. SDSPAGE shows input and protein bound to beads.

D - Representative fluorescence images and quantification of in vivo tethering assays. U2OS cells containing a LacO array where co-transfected with CENP-A-GFP-Lacl with CAL1wT-V5 and also with CAL1-V5 carrying point mutations. Graph shows average of 2 experiments, error bars on graph represent standard deviation. $n \geq 60$, scale bar is $10 \mu \mathrm{m}\left({ }^{*} \mathrm{P}<0.05,{ }^{* *} \mathrm{P}<0.01\right)$. 
A
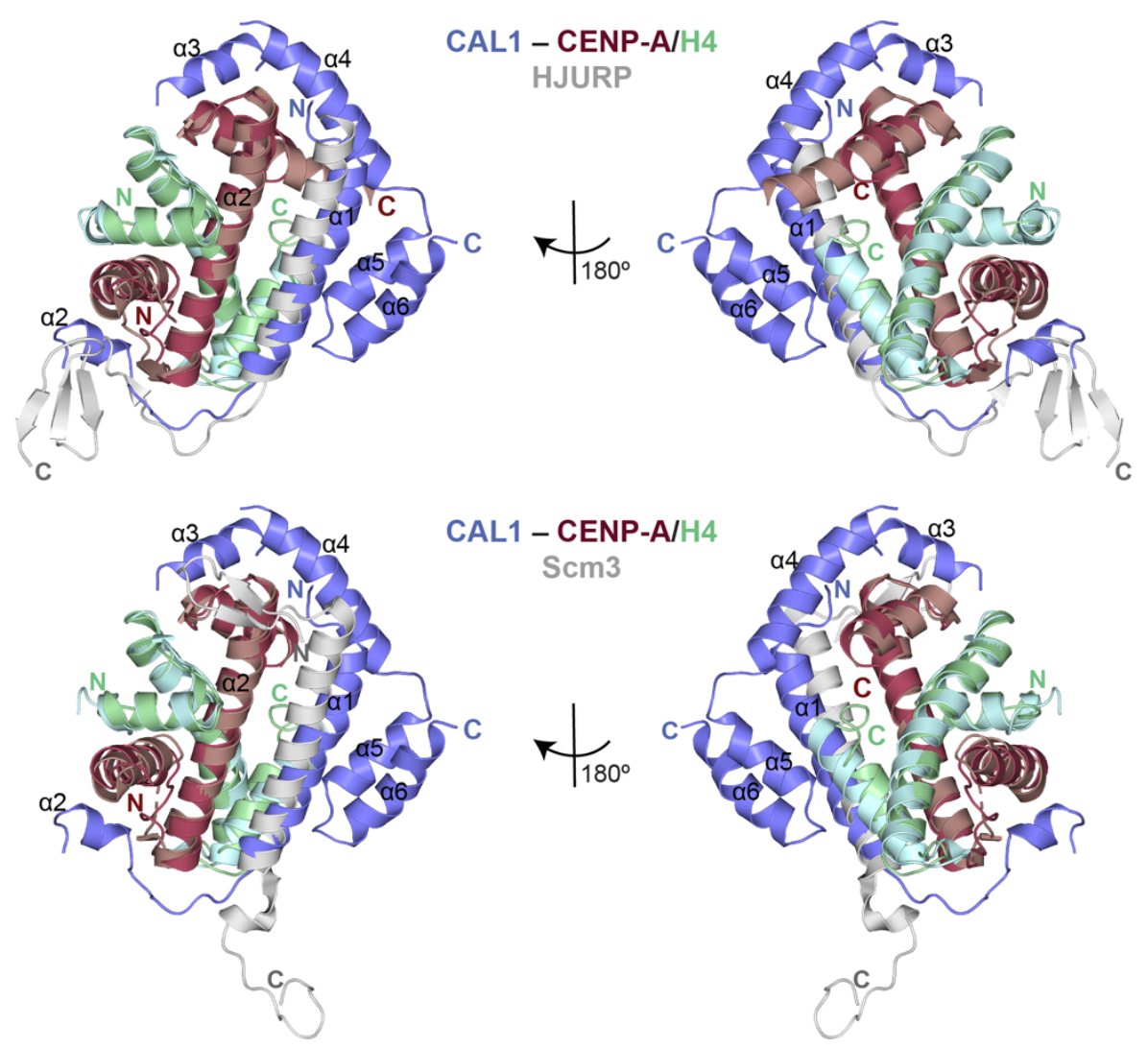

CAL1 - CENP-A/H4

$\mathrm{Scm} 3$
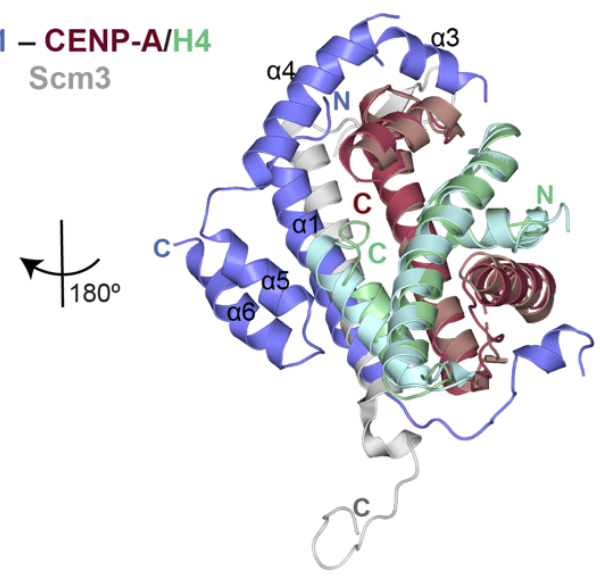

B
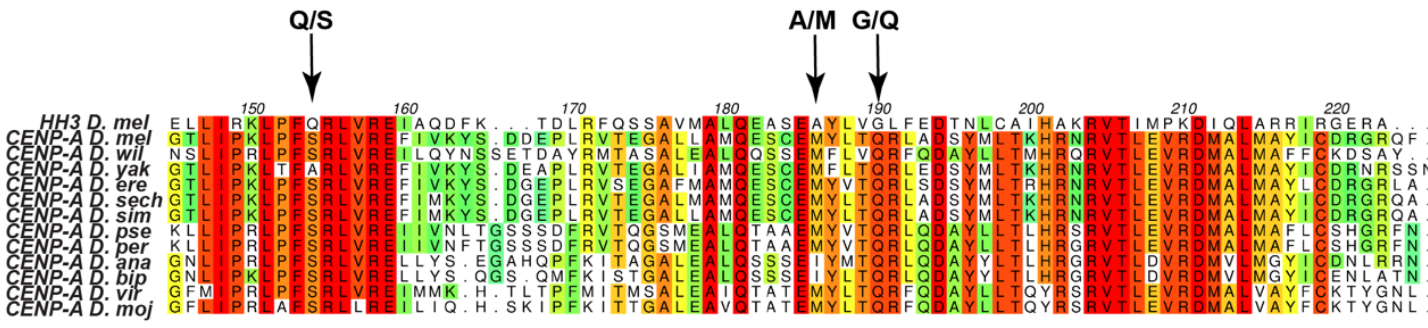

C

Input
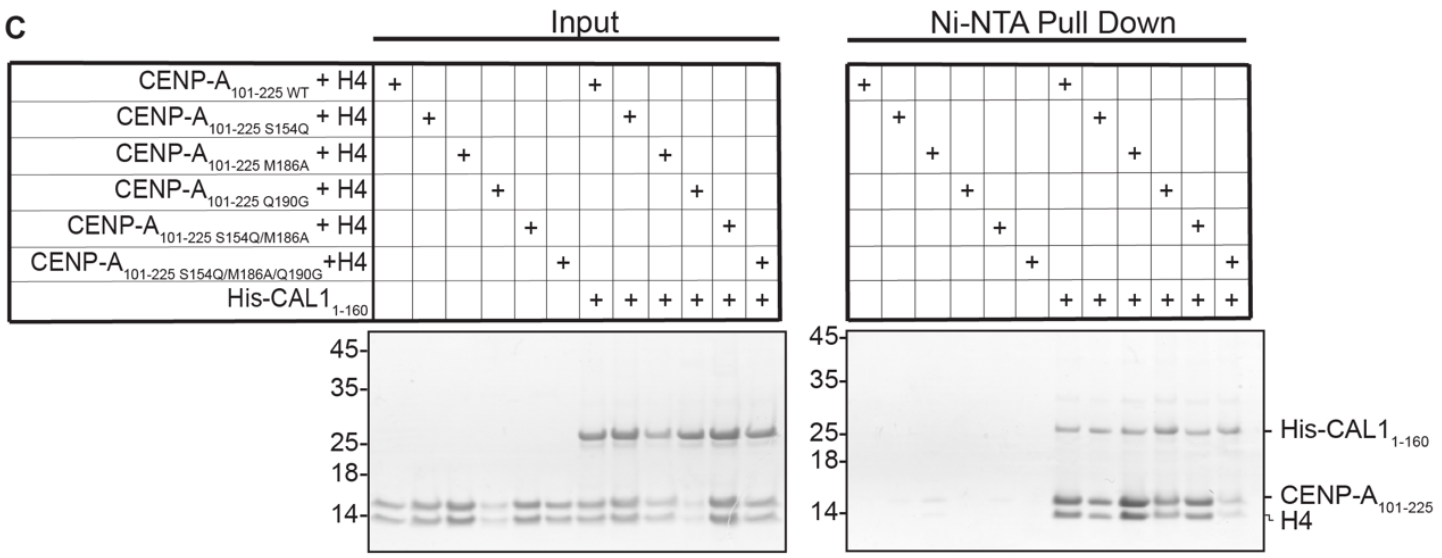

Figure 3 - CAL1 uses evolutionarily conserved and adaptive structural interactions to recognise Drosophila CENP-A/H4 
A - Upper panel shows structure of His-CAL1 ${ }_{1-160}-$ CENP-A $_{144-225}-\mathrm{H} 4$ superimposed with structure of human HJURP-CENP-A/H4 (Hu et al., 2011). CAL1 is shown in blue, CENP-A in maroon, $\mathrm{H} 4$ in green and HJURP shown in silver. Lower panel shows structure of His-CAL $1_{1}$ ${ }_{160}-\mathrm{CENP}-\mathrm{A}_{144-225}-\mathrm{H} 4$ superimposed with structure of yeast Scm3-CENP-A/H4 (Cho and Harrison, 2011). CAL1 is shown in blue, CENP-A in maroon, $\mathrm{H} 4$ in green and Scm3 shown in silver.

B - Alignment performed with MUSCLE (Madeira et al., 2019) showing conservation of CENPA homologues in different fly species in comparison to $d m \mathrm{H} 3$. Numbering corresponds to $D$. mel CENP-A. D. melanogaster (D. mel), D. willistoni (D. wil), D. yakuba (D. yak), D. erecta (D. ere), D. sechellia (D. sech), D. simulans (D. sim), D. pseudoobscura pseudoobscura $(D$. pse), D. persimilis (D. per), D. ananassae (D. ana), D. bipectinatal (D. bip), D. virilis (D. viri), and D. mojavensis (D. moj).

C - Ni-NTA pull-down of His-CAL1 1-160 wT with corresponding CENP-A ${ }_{101-225}-\mathrm{H} 4$ mutants. SDSPAGE shows input and protein bound to beads. 


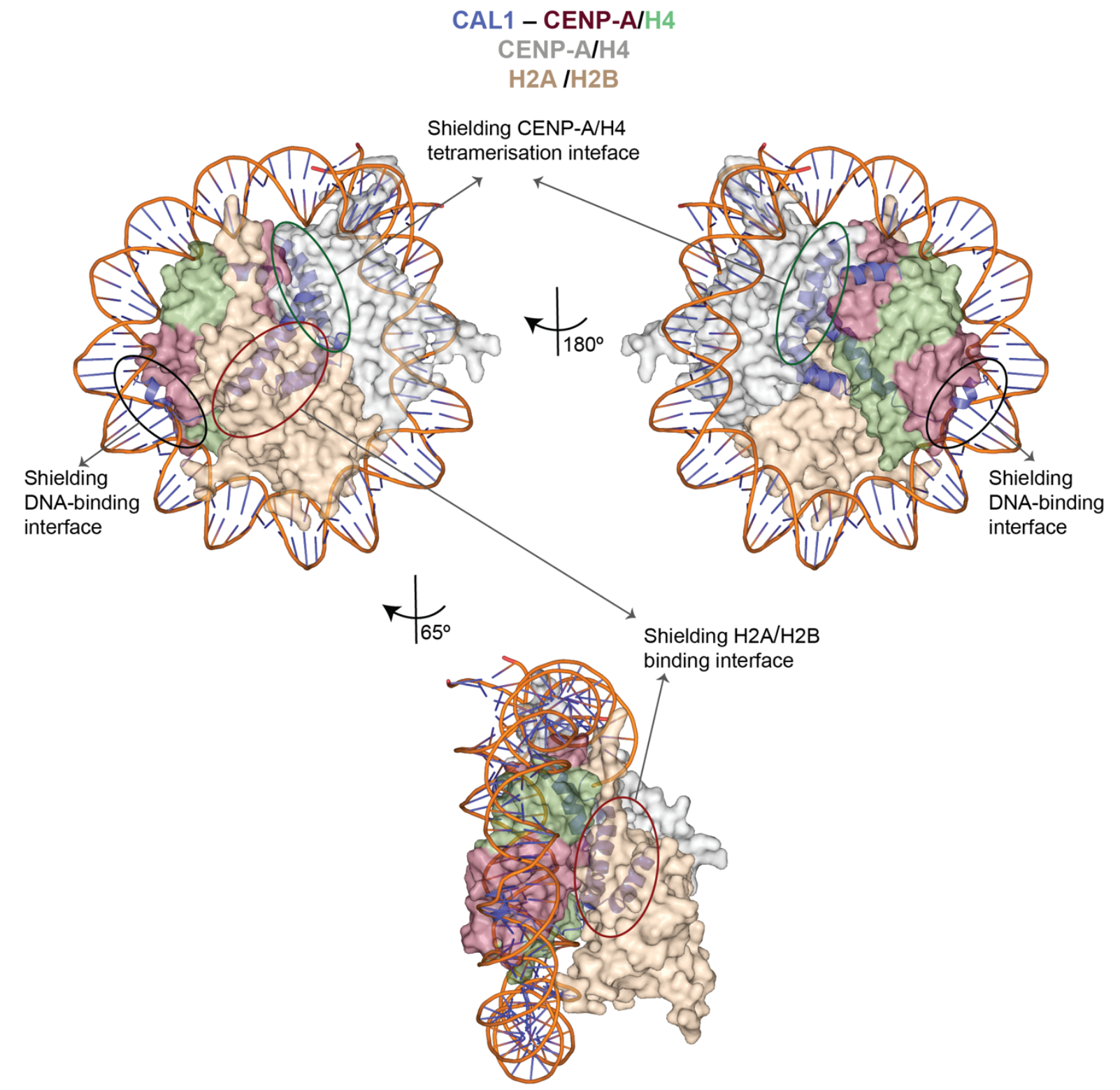

Figure 4 - CAL1 chaperones CENP-A/H4 by shielding the CENP-A/H4 tetramerisation,

\section{DNA-binding and H2A/H2B-binding interfaces}

Structure of His-CAL1 $1_{1-160}-\mathrm{CENP}-\mathrm{A}_{144-225}-\mathrm{H} 4$ superimposed with modeled structure of the $d m$ CENP-A nucleosome (Clapier et al., 2008). Different orientations highlighting mechanism for specificity to CENP-A/H4 dimer binding by CAL1. CENP-A/H4 and H2A/H2B are shown in surface representation. CAL1 and DNA are shown in cartoon representation. CENP-A and H4 bound to CAL 1 are shown in maroon and green while CAL1 in blue. 
A

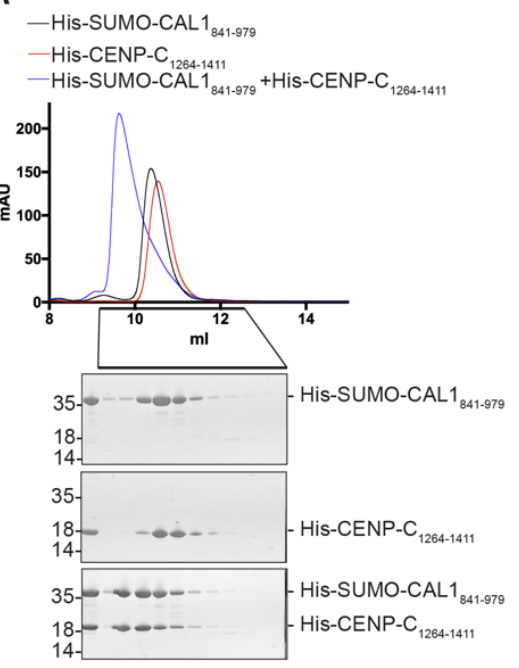

C

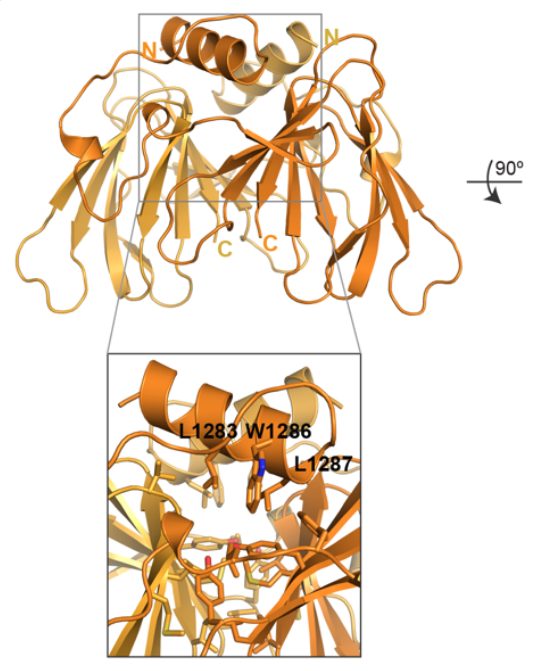

B

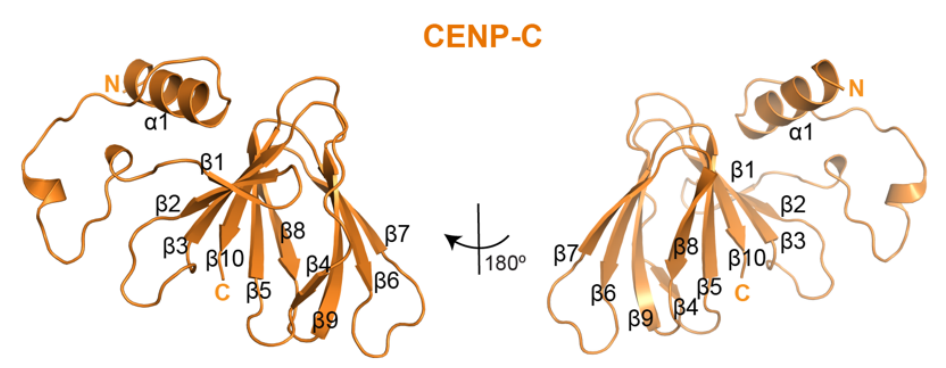

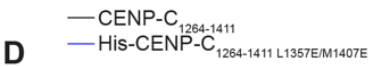

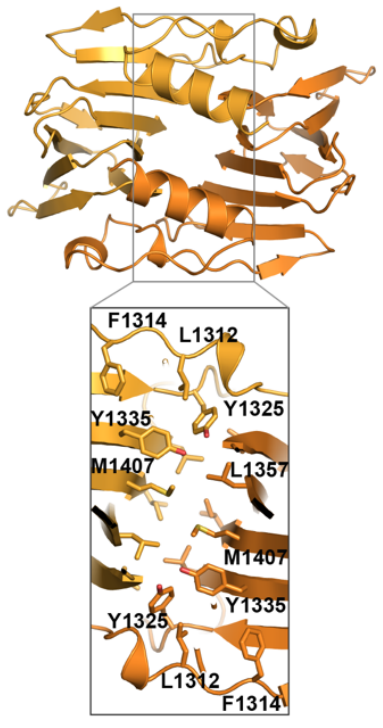

\begin{tabular}{|c|c|}
\hline $\begin{array}{c}\text { Measured MW in kDa } \\
\text { (calculated MW) }\end{array}$ & Number of subunits \\
\hline $34.4(17.2)$ & Dimer \\
\hline $20.2(19.2)$ & Monomer \\
\hline
\end{tabular}

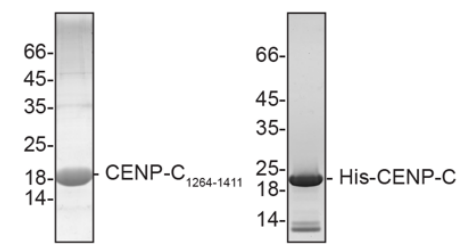

Figure 5 - CAL1 binds CENP-C by directly interacting with the evolutionarily conserved

\section{Cupin domain}

A - SEC profile of His-SUMO-CAL $1_{841-979}$ (black), His-CENP-C ${ }_{1264-1411}$ (red) and His-SUMO-

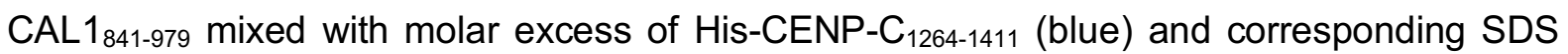
PAGE analysis of the fractions. Samples run on a Superdex 75 increase 10/300 in $20 \mathrm{mM}$ Tris-HCl pH8.0, $100 \mathrm{mM} \mathrm{NaCl}$ and $2 \mathrm{mM}$ DTT.

B - Crystal structure of CENP-C cupin domain determined at $1.7 \AA$ resolution.

C - Overall structure of CENP-C cupin domain dimer. Amino acids residues involved in dimerisation are highlighted in zoomed in panels. 


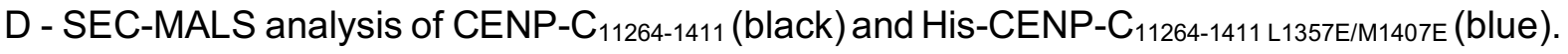

Absorption at $280 \mathrm{~nm}$ (mAU, left y-axis) and molecular mass (kDa, right y-axis) are plotted against elution volume ( $\mathrm{ml}, \mathrm{x}$-axis). Measured molecular weight (MW) and the calculated subunit stoichiometry based on the predicted MW of different subunit compositions. Samples run on either a Superdex 75 or a Superdex 200 increase 10/300 in 50 mM HEPES pH8.0, 100 $\mathrm{mM}$ or $300 \mathrm{mM} \mathrm{NaCl}$ and $1 \mathrm{mM}$ TCEP. 
A

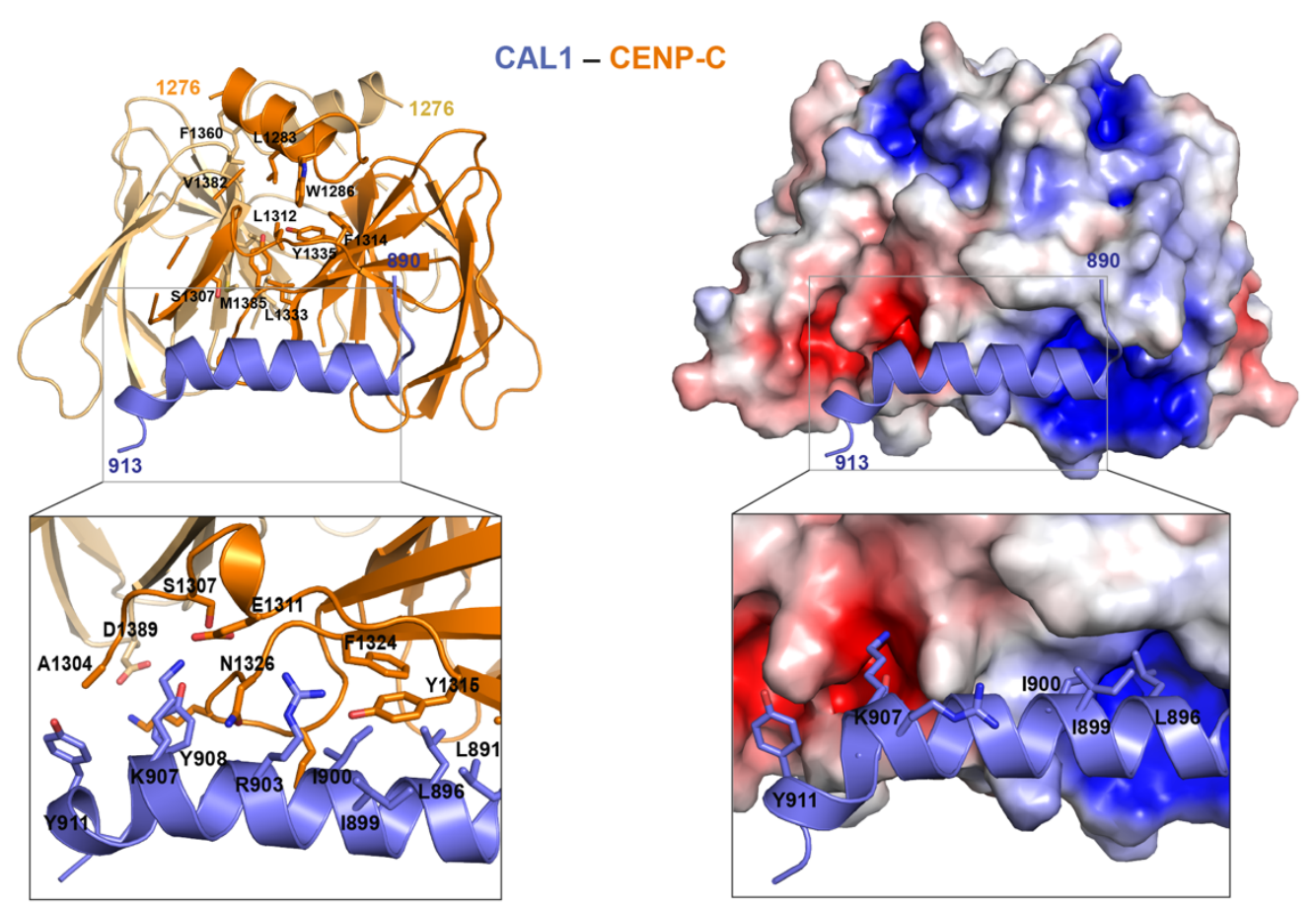

B

CENP-C

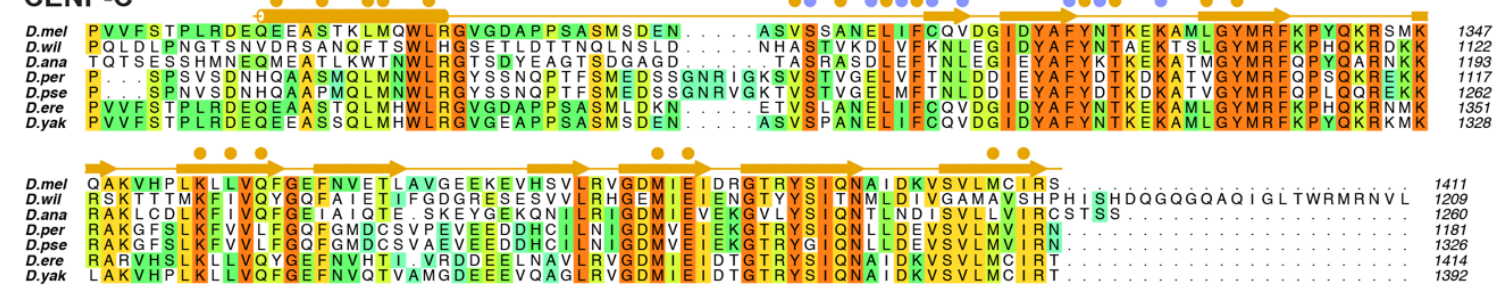

C

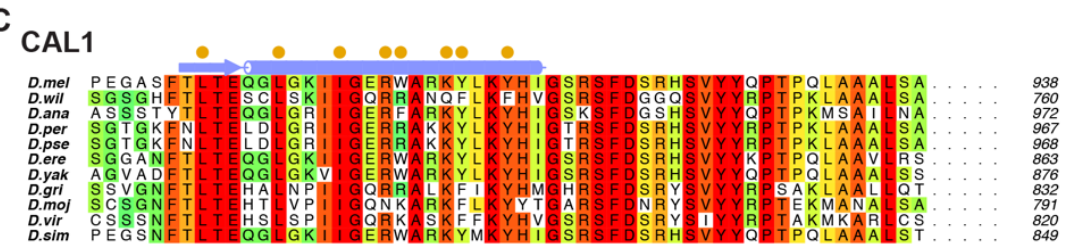

Figure 6 - Structural basis for CAL1 recognition by CENP-C cupin domain

A - (left panel) Crystal structure of CAL1 (shown in blue) bound CENP-C cupin domain (shown in orange) determined at $2.4 \AA$ resolution shown in cartoon representation. (right panel) CENP-C cupin domain is shown in surface representation colored based on electrostatic surface potential calculated using APBS. Zoomed in views highlight residues involved in interaction. 
B - Multiple sequence alignment performed with MUSCLE (Madeira et al., 2019) showing amino acid conservations of CENP-C homologues in different fly species. Residues involved in CENP-C cupin dimerisation and CAL1 binding are highlighted with filled orange and blue circles, respectively.

C - Multiple sequence alignment performed with MUSCLE (Madeira et al., 2019) showing conservations of C-terminus of CAL1 across its homologues in different fly species. Orange filled circles highlight the residues involved in CENP-C binding. D. melanogaster (D. mel), $D$. willistoni (D. wil), D. ananassae (D. ana), D. persimilis (D. per), D. pseudoobscura pseudoobscura (D. pse), D. erecta (D. ere), D. yakuba (D. yak), D. grimshawi (D. gri), D. mojavensis (D. moj), D. virilis (D. viri), and D. simulans (D. sim). 
bioRxiv preprint doi: https://doi.org/10.1101/723213; this version posted August 2, 2019. The copyright holder for this preprint (which was

not certified by peer review) is the author/funder, who has granted bioRxiv a license to display the preprint in perpetuity. It is made available under aCC-BY-NC-ND 4.0 International license.

A

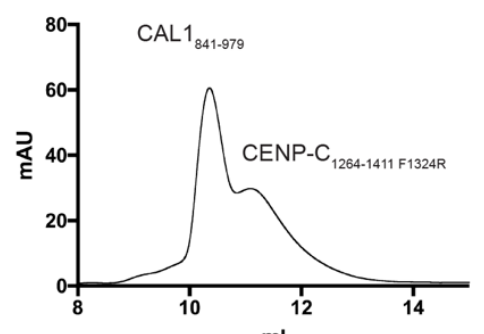

$\mathrm{ml}$

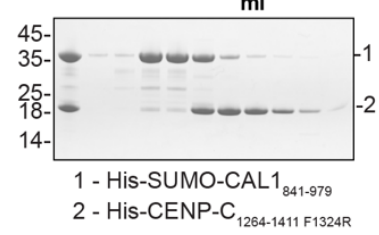

B

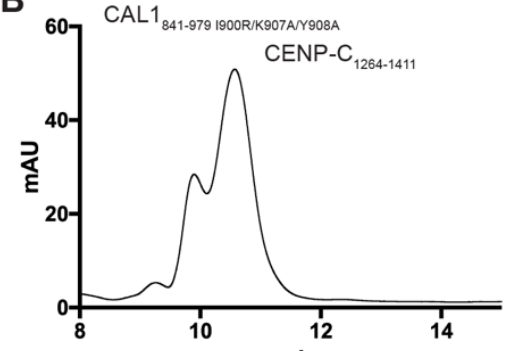

$\mathrm{ml}$

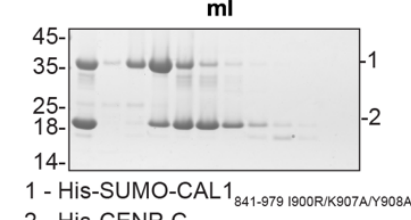

2 - His-CENP-C
C
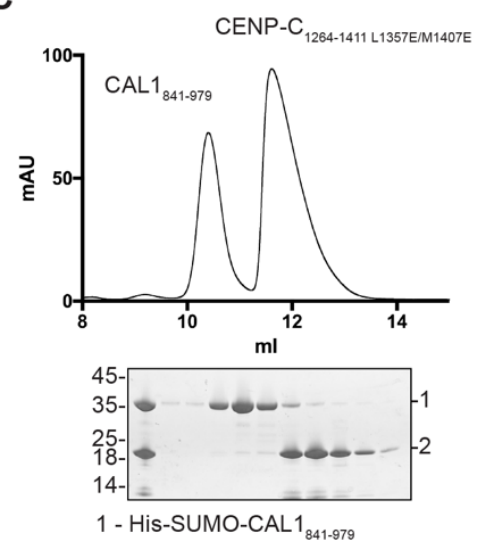

2 - His-CENP-C

D
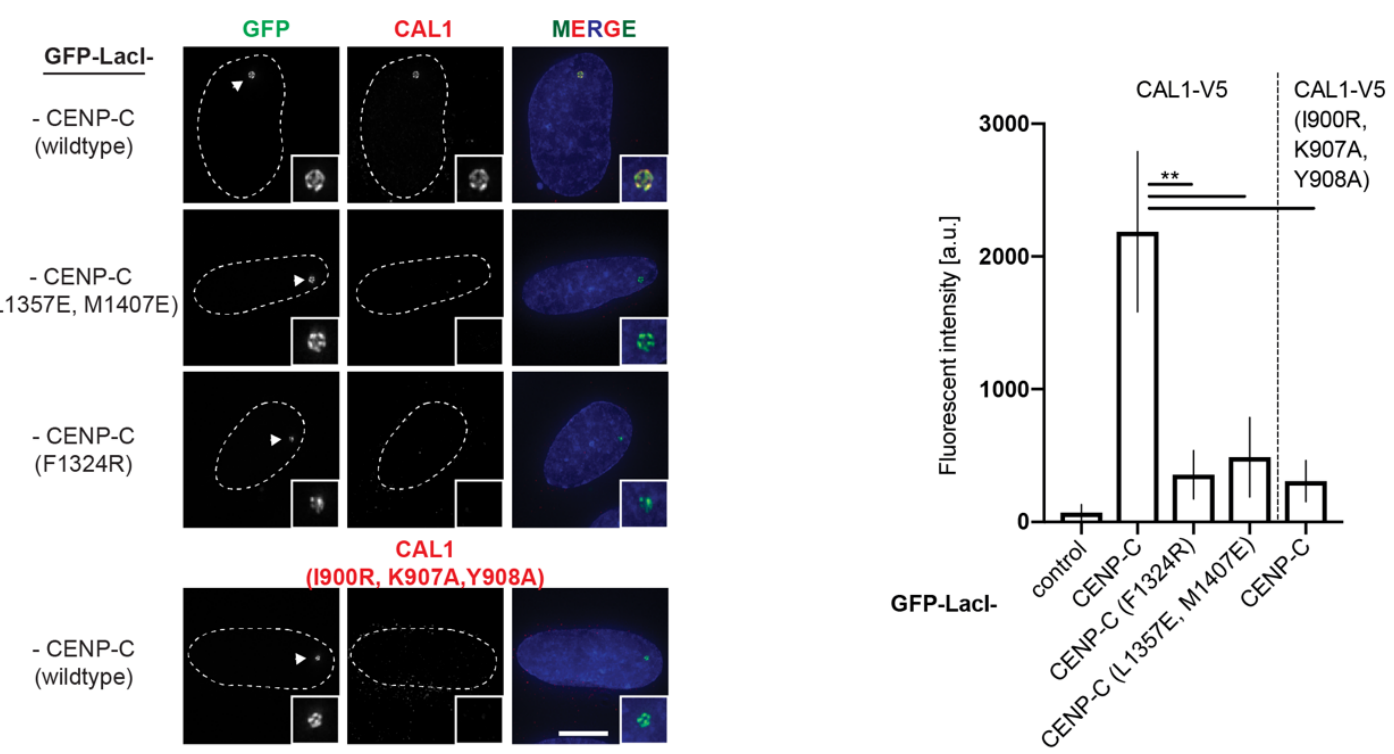

E
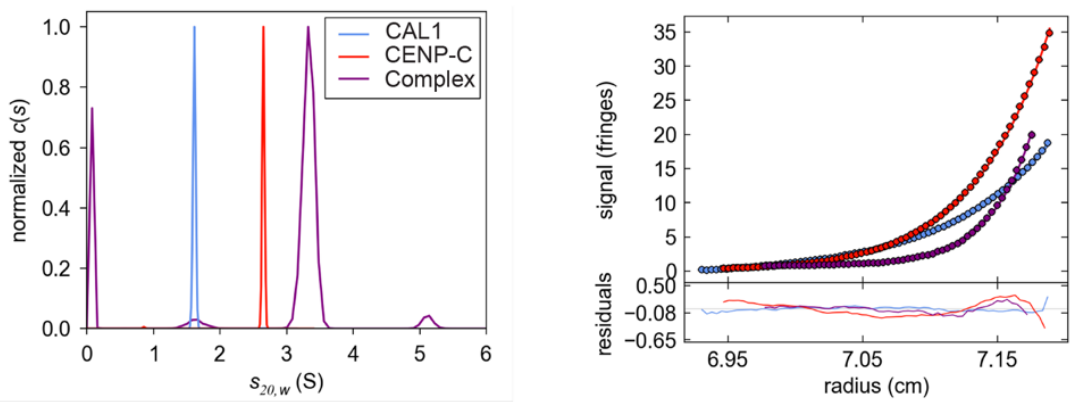

F
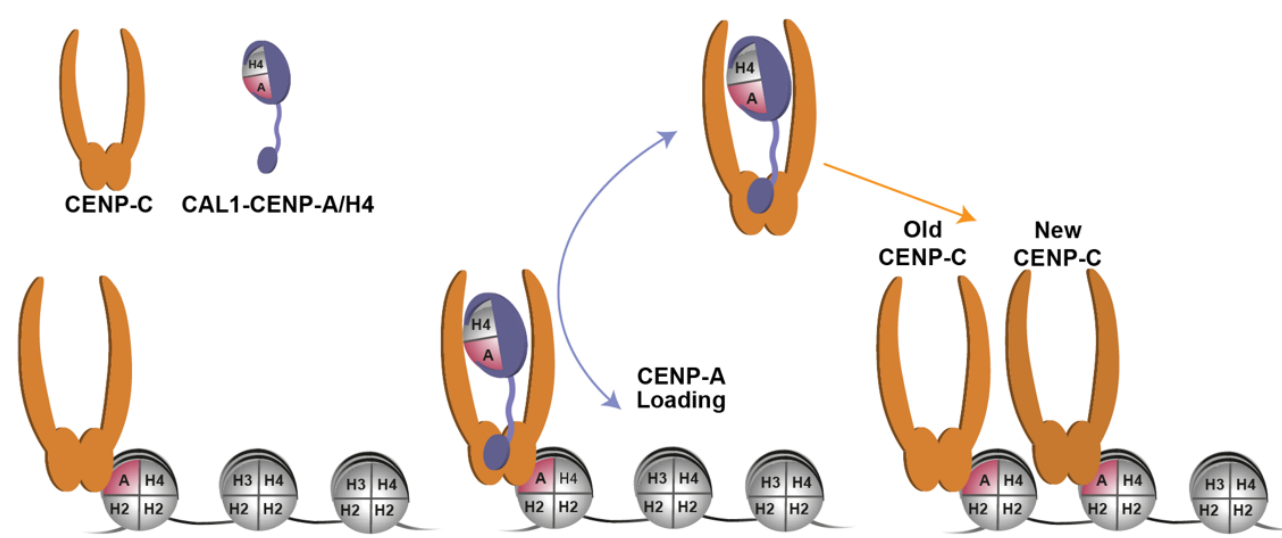


\section{Figure 7 - CENP-C cupin dimerisation is critical for CAL1 binding}

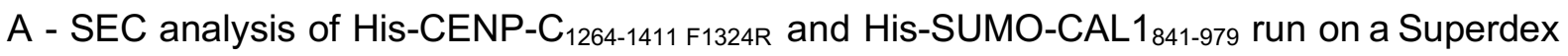
75 in $20 \mathrm{mM}$ Tris- $\mathrm{HCl}$ pH8.0, $0.1 \mathrm{M} \mathrm{NaCl}$ and $2 \mathrm{mM}$ DTT. Corresponding fractions shown by SDS-PAGE with commassie stain underneath.

B - SEC analysis of His-CENP-C ${ }_{11264-1411}$ and His-SUMO-CAL1 $1841-979$ 1900R/K907A/Y908A run on a Superdex 75 in $20 \mathrm{mM}$ Tris pH8.0, 0.1 M NaCl and $2 \mathrm{mM}$ DTT. Corresponding fractions shown by SDS-PAGE underneath.

C - SEC analysis of His-CENP-C ${ }_{11264-1411}$ L1357E/M1407E and His-SUMO-CAL1 $_{841-979}$ run on a Superdex 75 in $20 \mathrm{mM}$ Tris pH8.0, 0.1 M NaCl and 2mM DTT. Corresponding fractions shown by SDS-PAGE underneath.

D - Representative IF images and quantification of in vivo tethering assays. U2OS cells containing a LacO array where transfected with GFP-Lacl-CENP-C with CAL1-V5 to assess interaction. CENP-C mutants F1324R, L1357E/M1407E and CAL1 mutant 1900R/K907A/Y908A were tested in each construct separately. Graph shows average of 3 experiments, error bars on graph represent standard deviation. $n \geq 136$, scale bar is $\left({ }^{*} P<0.05\right.$, $\left.{ }^{* *} \mathrm{P}<0.01\right)$

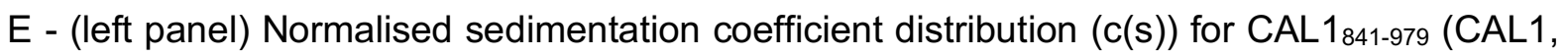
blue), CENP-C ${ }_{1264-1411}$ (CENP-C, red) and their equimolar mix (Complex, purple) all at 10 $\mathrm{mg} / \mathrm{ml}$, demonstrating a significant increase in $\boldsymbol{s}_{\mathbf{2 0 , w}}^{\mathbf{0}}$ consistent with the formation of a $2: 1$ complex.

(right panel) Typical sedimentation equilibrium data for CAL1 ${ }_{841-979}$ (CAL1, blue), CENP-C ${ }_{1264-}$ 1411 (CENP-C, red) and their equimolar mix (Complex, purple) all at $10 \mathrm{mg} / \mathrm{ml}$, demonstrating a significant increase in mass, consistent with the formation of a 2:1 complex. The data were fit with a single species model yielding masses of $20,253,29,216$ and $49,539 \mathrm{~g} / \mathrm{mol}$. The values reported in Figure S6 are based on data acquired for a range of concentrations.

See also Figures S5B

F - Schematic model of CAL1-mediated loading of CENP-A/H4 and CENP-C at centromeres. 


\section{References}

ADAMS, P. D., AFONINE, P. V., BUNKOCZI, G., CHEN, V. B., DAVIS, I. W., ECHOLS, N., HEADD, J. J., HUNG, L.-W., KAPRAL, G. J., GROSSE-KUNSTLEVE, R. W., MCCOY, A. J., MORIARTY, N. W., OEFFNER, R., READ, R. J., RICHARDSON, D. C., RICHARDSON, J. S., TERWILLIGER, T. C. \& ZWART, P. H. 2010. PHENIX: a comprehensive Python-based system for macromolecular structure solution. Acta Crystallographica Section D, 66, 213-221.

BROOKES, E. \& ROCCO, M. 2018. Recent advances in the UltraScan SOlution MOdeller (USSOMO) hydrodynamic and small-angle scattering data analysis and simulation suite. European Biophysics Journal, 47, 855-864.

CHEN, C.-C., DECHASSA, M. L., BETTINI, E., LEDOUX, M. B., BELISARIO, C., HEUN, P., LUGER, K. \& MELLONE, B. G. 2014. CAL1 is the Drosophila CENP-A assembly factor. The Journal of Cell Biology, 204, 313-329.

CHO, U. S. \& HARRISON, S. C. 2011. Recognition of the centromere-specific histone Cse4 by the chaperone Scm3. Proc Natl Acad Sci U S A, 108, 9367-71.

CLAPIER, C. R., CHAKRAVARTHY, S., PETOSA, C., FERNANDEZ-TORNERO, C., LUGER, K. \& MULLER, C. W. 2008. Structure of the Drosophila nucleosome core particle highlights evolutionary constraints on the H2A-H2B histone dimer. Proteins, 71, 1-7.

COHEN, R. L., ESPELIN, C. W., DE WULF, P., SORGER, P. K., HARRISON, S. C. \& SIMONS, K. T. 2008. Structural and functional dissection of Mif2p, a conserved DNA-binding kinetochore protein. Molecular biology of the cell, 19, 4480-4491.

DAMBACHER, S., DENG, W., HAHN, M., SADIC, D., FRÖHLICH, J., NUBER, A., HOISCHEN, C., DIEKMANN, S., LEONHARDT, H. \& SCHOTTA, G. 2012. CENP-C facilitates the recruitment of M18BP1 to centromeric chromatin. Nucleus (Austin, Tex.), 3, 101-110.

DIMAIO, F., ECHOLS, N., HEADD, J. J., TERWILLIGER, T. C., ADAMS, P. D. \& BAKER, D. 2013. Improved low-resolution crystallographic refinement with Phenix and Rosetta. Nature methods, 10, 1102-1104.

DRINNENBERG, I. A., DEYOUNG, D., HENIKOFF, S. \& MALIK, H. S. 2014. Recurrent loss of CenH3 is associated with independent transitions to holocentricity in insects. Elife, 3.

DUNLEAVY, E. M., ALMOUZNI, G. \& KARPEN, G. H. 2011. H3.3 is deposited at centromeres in $S$ phase as a placeholder for newly assembled CENP-A in G(1) phase. Nucleus, 2, 14657.

DUNLEAVY, E. M., ROCHE, D., TAGAMI, H., LACOSTE, N., RAY-GALLET, D., NAKAMURA, Y., DAIGO, Y., NAKATANI, Y. \& ALMOUZNI-PETTINOTTI, G. 2009. HJURP is a cell-cycledependent maintenance and deposition factor of CENP-A at centromeres. Cell, 137, 485-497.

EMSLEY, P. \& COWTAN, K. 2004. Coot: model-building tools for molecular graphics. Acta Crystallogr D Biol Crystallogr, 60, 2126-32.

ERHARDT, S., MELLONE, B. G., BETTS, C. M., ZHANG, W., KARPEN, G. H. \& STRAIGHT, A. F. 2008. Genome-wide analysis reveals a cell cycle-dependent mechanism controlling centromere propagation. The Journal of Cell Biology, 183, 805-818.

FOLTZ, D. R., JANSEN, L. E. T., BAILEY, A. O., YATES, I., JOHN R, BASSETT, E. A., WOOD, S., BLACK, B. E. \& CLEVELAND, D. W. 2009. Centromere-specific assembly of CENP-a nucleosomes is mediated by HJURP. Cell, 137, 472-484.

FRENCH, B. T. \& STRAIGHT, A. F. 2019. CDK phosphorylation of Xenopus laevis M18BP1 promotes its metaphase centromere localization. Embo j, 38. 
FRENCH, B. T., WESTHORPE, F. G., LIMOUSE, C. \& STRAIGHT, A. F. 2017. Xenopus laevis M18BP1 Directly Binds Existing CENP-A Nucleosomes to Promote Centromeric Chromatin Assembly. Dev Cell, 42, 190-199.e10.

FUJITA, Y., HAYASHI, T., KIYOMITSU, T., TOYODA, Y., KOKUBU, A., OBUSE, C. \& YANAGIDA, M. 2007. Priming of centromere for CENP-A recruitment by human hMis18alpha, hMis18beta, and M18BP1. Developmental Cell, 12, 17-30.

GOSHIMA, G., WOLLMAN, R., GOODWIN, S. S., ZHANG, N., SCHOLEY, J. M., VALE, R. D. \& STUURMAN, N. 2007. Genes required for mitotic spindle assembly in Drosophila S2 cells. Science (New York, N.Y.), 316, 417-421.

GROSSE-KUNSTLEVE, R. W., SAUTER, N. K., MORIARTY, N. W. \& ADAMS, P. D. 2002. The Computational Crystallography Toolbox: crystallographic algorithms in a reusable software framework. Journal of Applied Crystallography, 35, 126-136.

HAMMOND, C. M., STR ØMME, C. B., HUANG, H., PATEL, D. J. \& GROTH, A. 2017. Histone chaperone networks shaping chromatin function. Nature reviews. Molecular cell biology, 18, 141-158.

HAYASHI, T., EBE, M., NAGAO, K., KOKUBU, A., SAJIKI, K. \& YANAGIDA, M. 2014. Schizosaccharomyces pombe centromere protein Mis19 links Mis16 and Mis18 to recruit CENP-A through interacting with NMD factors and the SWI/SNF complex. Genes to cells

HAYASHI, T., FUJITA, Y., IWASAKI, O., ADACHI, Y., TAKAHASHI, K. \& YANAGIDA, M. 2004. Mis16 and Mis18 Are Required for CENP-A Loading and Histone Deacetylation at Centromeres. Cell, 118, 715-729.

HAYES, D. B., LAUE, T. M., PHILO, J., HURTON, T., WRIGHT, A., DEUBLER, G. \& BASHIR, B. 2012. SEDNTERP.

HEMMERICH, P., WEIDTKAMP-PETERS, S., HOISCHEN, C., SCHMIEDEBERG, L., ERLIANDRI, I. \& DIEKMANN, S. 2008. Dynamics of inner kinetochore assembly and maintenance in living cells. J Cell Biol, 180, 1101-14.

HORI, T., SHANG, W. H., HARA, M., ARIYOSHI, M., ARIMURA, Y., FUJITA, R., KURUMIZAKA, H. \& FUKAGAWA, T. 2017. Association of M18BP1/KNL2 with CENP-A Nucleosome Is Essential for Centromere Formation in Non-mammalian Vertebrates. Dev Cell, 42, 181189.e3.

HU, H., LIU, Y., WANG, M., FANG, J., HUANG, H., YANG, N., LI, Y., WANG, J., YAO, X., SHI, Y., LI, G. \& XU, R.-M. 2011. Structure of a CENP-A-histone $H 4$ heterodimer in complex with chaperone HJURP. Genes \& Development, 25, 901-906.

JANICKI, S. M., TSUKAMOTO, T., SALGHETTI, S. E., TANSEY, W. P., SACHIDANANDAM, R., PRASANTH, K. V., RIED, T., SHAV-TAL, Y., BERTRAND, E., SINGER, R. H. \& SPECTOR, D. L. 2004. From silencing to gene expression: real-time analysis in single cells. Cell, 116, 683-98.

JANSEN, L. E., BLACK, B. E., FOLTZ, D. R. \& CLEVELAND, D. W. 2007. Propagation of centromeric chromatin requires exit from mitosis. J Cell Biol, 176, 795-805.

KABSCH, W. 2010. XDS. Acta Crystallographica Section D, 66, 125-132.

KATO, T., SATO, N., HAYAMA, S., YAMABUKI, T., ITO, T., MIYAMOTO, M., KONDO, S., NAKAMURA, Y. \& DAIGO, Y. 2007. Activation of Holliday junction recognizing protein involved in the chromosomal stability and immortality of cancer cells. Cancer Res, 67, 8544-53.

KESSNER, D., CHAMBERS, M., BURKE, R., AGUS, D. \& MALLICK, P. 2008. ProteoWizard: open source software for rapid proteomics tools development. Bioinformatics, 24, 2534-6. 
LENZ, S., GIESE, S. H., FISCHER, L. \& RAPPSILBER, J. 2018. In-Search Assignment of Monoisotopic Peaks Improves the Identification of Cross-Linked Peptides. J Proteome Res, 17, 3923-3931.

LIDSKY, P. V., SPRENGER, F. \& LEHNER, C. F. 2013. Distinct modes of centromere protein dynamics during cell cycle progression in Drosophila S2R+ cells. J Cell Sci, 126, 478293.

MADEIRA, F., PARK, Y. M., LEE, J., BUSO, N., GUR, T., MADHUSOODANAN, N., BASUTKAR, P., TIVEY, A. R. N., POTTER, S. C., FINN, R. D. \& LOPEZ, R. 2019. The EMBL-EBI search and sequence analysis tools APIs in 2019. Nucleic Acids Res, 47, W636-w641.

MCCOY, A. J., GROSSE-KUNSTLEVE, R. W., ADAMS, P. D., WINN, M. D., STORONI, L. C. \& READ, R. J. 2007. Phaser crystallographic software. J Appl Crystallogr, 40, 658-674.

MCKINLEY, K. L. \& CHEESEMAN, I. M. 2014. Polo-like kinase 1 licenses CENP-A deposition at centromeres. Cell, 158, 397-411.

MCKINLEY, K. L. \& CHEESEMAN, I. M. 2016. The molecular basis for centromere identity and function. Nat Rev Mol Cell Biol, 17, 16-29.

MELLONE, B. G., GRIVE, K. J., SHTEYN, V., BOWERS, S. R., ODERBERG, I. \& KARPEN, G. H. 2011. Assembly of Drosophila centromeric chromatin proteins during mitosis. PLoS Genet, 7, e1002068.

MENDES, M. L., FISCHER, L., CHEN, Z. A., BARBON, M., O'REILLY, F. J., BOHLKE-SCHNEIDER, M., BELSOM, A., DAU, T., COMBE, C. W., GRAHAM, M., EISELE, M. R., BAUMEISTER, W., SPECK, C. \& RAPPSILBER, J. 2018. An integrated workflow for cross-linking/mass spectrometry. bioRxiv.

MOREE, B., MEYER, C. B., FULLER, C. J. \& STRAIGHT, A. F. 2011. CENP-C recruits M18BP1 to centromeres to promote CENP-A chromatin assembly. The Journal of Cell Biology, 194, 855-871.

MUSACCHIO, A. \& DESAI, A. 2017. A Molecular View of Kinetochore Assembly and Function. Biology (Basel), 6.

NARDI, I. K., ZASADZIŃSKA, E., STELLFOX, M. E., KNIPPLER, C. M. \& FOLTZ, D. R. 2016. Licensing of Centromeric Chromatin Assembly through the Mis18\&amp;alpha;Mis18\&amp; beta; Heterotetramer. Molecular Cell, 61, 774-787.

PAN, D., KLARE, K., PETROVIC, A., TAKE, A., WALSTEIN, K., SINGH, P., RONDELET, A., BIRD, A. W. \& MUSACCHIO, A. 2017. CDK-regulated dimerization of M18BP1 on a Mis18 hexamer is necessary for CENP-A loading. Elife, 6.

PHANSALKAR, R., LAPIERRE, P. \& MELLONE, B. G. 2012. Evolutionary insights into the role of the essential centromere protein CAL1 in Drosophila. Chromosome research : an international journal on the molecular, supramolecular and evolutionary aspects of chromosome biology, 20, 493-504.

PIDOUX, A. L., CHOI, E. S., ABBOTT, J. K. R., LIU, X., KAGANSKY, A., CASTILLO, A. G., HAMILTON, G. L., RICHARDSON, W., RAPPSILBER, J., HE, X. \& ALLSHIRE, R. C. 2009. Fission yeast Scm3: A CENP-A receptor required for integrity of subkinetochore chromatin. Molecular Cell, 33, 299-311.

RAPPSILBER, J., MANN, M. \& ISHIHAMA, Y. 2007. Protocol for micro-purification, enrichment, pre-fractionation and storage of peptides for proteomics using StageTips. Nat Protoc, 2, 1896-906.

ROSIN, L. \& MELLONE, B. G. 2016. Co-evolving CENP-A and CAL1 Domains Mediate Centromeric CENP-A Deposition across Drosophila Species. Developmental Cell, 37, 136-147. 
ROURE, V., MEDINA-PRITCHARD, B., ANSELM, E., JEYAPRAKASH, A. A. \& HEUN, P. 2019. Epigenetic inheritance of centromere identity in a heterologous system. bioRxiv.

SANCHEZ-PULIDO, L., PIDOUX, A. L., PONTING, C. P. \& ALLSHIRE, R. C. 2009. Common ancestry of the CENP-A chaperones Scm3 and HJURP. Cell, 137, 1173-4.

SCHITTENHELM, R. B., ALTHOFF, F., HEIDMANN, S. \& LEHNER, C. F. 2010. Detrimental incorporation of excess Cenp-A/Cid and Cenp-C into Drosophila centromeres is prevented by limiting amounts of the bridging factor Cal1. Journal of Cell Science, 123, 3768-3779.

SCHUCK, P. 2000. Size-distribution analysis of macromolecules by sedimentation velocity ultracentrifugation and Lamm equation modeling. Biophysical Journal, 78, 1606-1619.

SEKULIC, N. \& BLACK, B. E. 2012. Molecular underpinnings of centromere identity and maintenance. Trends Biochem Sci, 37, 220-9.

SILVA, M. C. C., BODOR, D. L., STELLFOX, M. E., MARTINS, N. M. C., HOCHEGGER, H., FOLTZ, D. R. \& JANSEN, L. E. T. 2012. Cdk activity couples epigenetic centromere inheritance to cell cycle progression. Developmental Cell, 22, 52-63.

SPILlER, F., MEDINA, B., ABAD, M. A., WEAR, M. A., MOLINA, O., EARNSHAW, W. C. \& JEYAPRAKASH, A. A. 2017. Molecular basis for Cdk1-regulated timing of Mis18 complex assembly and CENP-A deposition. EMBO reports, 18, 894-905.

STANKOVIC, A., GUO, L. Y., MATA, J. F., BODOR, D. L., CAO, X. J., BAILEY, A. O., SHABANOWITZ, J., HUNT, D. F., GARCIA, B. A., BLACK, B. E. \& JANSEN, L. E. T. 2017. A Dual Inhibitory Mechanism Sufficient to Maintain Cell-Cycle-Restricted CENP-A Assembly. Mol Cell, 65, 231-246.

STELLFOX, M. E., BAILEY, A. O. \& FOLTZ, D. R. 2012. Putting CENP-A in its place. Cellular and Molecular Life Sciences, 70, 387-406.

STELLFOX, M. E., NARDI, I. K., KNIPPLER, C. M. \& FOLTZ, D. R. 2016. Differential Binding Partners of the Mis18 $\alpha / \beta$ YIPPEE Domains Regulate Mis18 Complex Recruitment to Centromeres. Cell reports, 15, 2127-2135.

SUBRAMANIAN, L., TODA, N. R. T., RAPPSILBER, J. \& ALLSHIRE, R. C. 2014. Eic1 links Mis18 with the CCAN/Mis6/Ctf19 complex to promote CENP-A assembly. Open biology, 4, 140043.

TACHIWANA, H., MÜLLER, S., BLÜMER, J., KLARE, K., MUSACCHIO, A. \& ALMOUZNI, G. 2015. HJURP involvement in de novo CenH3(CENP-A) and CENP-C recruitment. Cell reports, $11,22-32$.

TICKLE, I. J., FLENSBURG, C., KELLER, P., PACIOREK, W., SHARFF, A., VONRHEIN, C. \& BRICOGNE, G. 2018. STARANISO, Cambridge, United Kingdom: Global Phasing Ltd.

VISTICA, J., DAM, J., BALBO, A., YIKILMAZ, E., MARIUZZA, R. A., ROUAULT, T. A. \& SCHUCK, P. 2004. Sedimentation equilibrium analysis of protein interactions with global implicit mass conservation constraints and systematic noise decomposition. Analytical Biochemistry, 326, 234-256.

VONRHEIN, C., FLENSBURG, C., KELLER, P., SHARFF, A., SMART, O., PACIOREK, W., WOMACK, T. \& BRICOGNE, G. 2011. Data processing and analysis with the autoPROC toolbox. Acta Crystallogr D Biol Crystallogr, 67, 293-302.

WESTHORPE, F. G. \& STRAIGHT, A. F. 2014. The centromere: epigenetic control of chromosome segregation during mitosis. Cold Spring Harb Perspect Biol, 7, a015818.

WINN, M. D., BALLARD, C. C., COWTAN, K. D., DODSON, E. J., EMSLEY, P., EVANS, P. R., KEEGAN, R. M., KRISSINEL, E. B., LESLIE, A. G. W., MCCOY, A., MCNICHOLAS, S. J., MURShUdoV, G. N., PANNU, N. S., POTTERTON, E. A., POWELL, H. R., READ, R. J., 
VAGIN, A. \& WILSON, K. S. 2011. Overview of the CCP4 suite and current developments. Acta crystallographica. Section D, Biological crystallography, 67, 235242.

WINTER, G. \& MCAULEY, K. E. 2011. Automated data collection for macromolecular crystallography. Methods, 55, 81-93.

ZASADZINSKA, E. \& FOLTZ, D. R. 2017. Orchestrating the Specific Assembly of Centromeric Nucleosomes. Prog Mol Subcell Biol, 56, 165-192. 